\title{
Predictability of prototype flash flood events in the Western Mediterranean under uncertainties of the precursor upper-level disturbance: the HYDROPTIMET case studies
}

\author{
R. Romero, A. Martín, V. Homar, S. Alonso, and C. Ramis \\ Meteorology Group, Departament de Física, Universitat de les Illes Balears, Palma de Mallorca, Spain \\ Received: 24 March 2005 - Revised: 21 June 2005 - Accepted: 1 July 2005 - Published: 27 July 2005
}

Part of Special Issue "HYDROPTIMET"

\begin{abstract}
The HYDROPTIMET case studies (9-10 June 2000 Catalogne, 8-9 September 2002 Cévennes and 2426 November 2002 Piémont) appear to encompass a sort of prototype flash-flood situations in the western Mediterranean attending to the relevant synoptic and mesoscale signatures identified on the meteorological charts. In Catalogne, the convective event was driven by a low-pressure system of relatively small dimensions developed over the mediterranean coast of Spain that moved into southern France. For Cévennes, the main circulation pattern was a synoptic-scale Atlantic low which induced a persistent southerly low-level jet (LLJ) over the western Mediterranean, strengthened by the Alps along its western flank, which guaranteed continuous moisture supply towards southern France where the longlived, quasistationary convective system developed. The long Piémont episode, very representative of the most severe alpine flash flood events, shares some similarities with the Cévennes situation during its first stage in that it was controlled by a southerly moist LLJ associated with a large-scale disturbance located to the west. However, these circulation features were transient aspects and during the second half of the episode the situation was dominated by a cyclogenesis process over the Mediterranean which gave place to a mesoscale-size depression at surface that acted to force new heavy rain over the slopes of the Alps and maritime areas. That is, the Piémont episode can be catalogued as of mixed type with regard to the responsible surface disturbance, evolving from a large-scale pattern with remote action (like Cévennes) to a mesoscale pattern with local action (like Catalogne).
\end{abstract}

A prominent mid-tropospheric trough or cut-off low can be identified in all events prior and during the period of heavy rain, which clearly served as the precursor agent for the onset of the flash-flood conditions and the cyclogenesis at lowlevels. Being aware of the uncertainty in the representation of the upper-level disturbance and the necessity to cope with

Correspondence to: R. Romero

(romu.romero@uib.es) it within the operational context when attempting to issue short to mid-range numerical weather predictions of these high impact weather events, a systematic exploration of the predictability of the three selected case studies subject to uncertainties in the representation of the upper-level precursor disturbance is carried out in this paper.

The study is based on an ensemble of mesoscale numerical simulations of each event with the MM5 non-hydrostatic model after perturbing in a systematic way the upper-level disturbance, in the sense of displacing slightly this disturbance upstream/downstream along the zonal direction and intensifying/weakening its amplitude. These perturbations are guided by a previous application of the MM5-adjoint model, which consistently shows high sensitivities of the dynamical control of the heavy rain to the flow configuration about the upper-level disturbance on the day before, thus confirming the precursor characteristics of this agent. The perturbations are introduced to the initial conditions by applying a potential vorticity $(\mathrm{PV})$ inversion procedure to the positive PV anomaly associated with the upper-level disturbance, and then using the inverted fields (wind, temperature and geopotential) to modify under a physically consistent balance the model initial fields. The results generally show that the events dominated by mesoscale low-level disturbances (Catalogne and last stage of the Piémont episode) are very sensitive to the initial uncertainties, such that the heavy rain location and magnitude are in some of the experiments strongly changed in response to the 'forecast errors' of the cyclone trajectory, intensity, shape and translational speed. In contrast, the other situations (Cévennes and initial stage of the Piémont episode), dominated by a larger scale system wich basically acts to guarantee the establishment and persistence of the southerly LLJ towards the southern France-north Italy orography, exhibit much higher predictability. That is, the slight modifications in the LLJ direction and intensity encompassed by the ensemble of perturbed forecasts are less critical with respect to the heavy precipitation potential and affected area. 


\section{Introduction}

The core subject of Interreg IIIB-Medocc HYDROPTIMET project is the improvement of the hydro-meteorological tools used in the western Mediterranean for the surveillance and prediction of flash floods. Two essential components are involved in the hydro-meteorological chain that must be taken into account when attempting to produce and disseminate reliable warnings to the public with sufficient lead times: the mesoscale atmospheric model and the rainfall-runoff model. Both models become important sources of uncertainty for the hydro-meteorological chain, mainly owing to the inherent uncertainty of the atmospheric initial state and to the typically small size of Mediterranean catchments for which any error in the spatial and quantitative predicted rainfall severely affects the hydrological simulation.

To overcome these limitations the hydro-meteorological research is rapidly advancing towards a combination of methodologies within a probabilistic framework (e.g. Ferraris et al., 2002). First, in the field of numerical atmospheric modelling, ensemble prediction systems (EPS) are used to estimate the forecast variance from a set of perturbations added to a reference initial condition (Murphy, 1988) in order to compute an ensemble of perturbed forecasts useful to generate a range of reasonable rainfall scenarios. EPS methodologies have long been used with relative success for synoptic-scale mid-range forecasting in the main world centres (e.g. ECMWF, NCEP, JMA), under diverse techniques for the generation of the ensemble members such as singular vectors (Buizza and Palmer, 1995) and breeding vectors (Toth and Kalnay, 1993). For the mesoscale short-range forecasting, where observed atmospheric fields include relatively larger errors and some complex processes like moist convection and turbulent mixing in the boundary layer play a major role, the generation and interpretation of ensembles is more problematic (Hamill et al., 2000). Recent studies recognize the role of model error and suggest constructing the mesoscale ensembles using multi-model, multiphysics configurations in addition to the conventional perturbation of initial conditions (Stensrud et al., 2000). Second, in order to generate precipitation fields coherent with hydrologic scales, disaggregation techniques are being applied where the large-scale meteorological predictions are disaggregated preserving the expected value of the rainfall at the large scale while introducing appropriate second- and upper-order moments of the probability distribution (Deidda et al., 1999; Deidda, 2000; Ferraris et al., 2002). Nowadays, it is clear that the implementation of probabilistic hydrometeorological methods before potentially dangerous meteorological situations allows better designed emergency procedures than the traditional-deterministic-approaches.

Understanding the characteristic predictability of the flash-flood situations in the western Mediterranean appears as a basic task for assessing the value of incorporating the meteorological uncertainty in the prediction system. Some studies have shown a relative insensitivity of mesoscale model results to the precise structure of initial and bound- ary conditions in areas with complex terrain (e.g. Mass and Kuo, 1998). Particular case studies of the western Mediterranean have emphasized that the synoptic-scale structures associated with the region's heavy rainfall events and the strong topographic influences combine to provide an opportunity for improved forecasting through the use of mesoscale model simulations, especially over the Alpine region (Romero et al., 1998). The predictability value offered by the complex topography would suggest a dedication of the increasing computational resources to enhanced model grid resolutions rather than to the ensemble approach, but in fact a combination of a very high resolution deterministic output with the lower-resolution ensemble members seems to be the optimum approach for improving the quantitative precipitation forecasts (Roebber et al., 2004). The dynamical control of the heavy precipitation episodes in the western Mediterranean region is typically exerted by the interaction of the moist low-level wind, such as a low-level jet (LLJ) possessing a long fetch over the sea, with the coastal mountain systems (e.g. Doswell et al., 1998; Romero, 2001). It could then be argued that flash-flood situations controlled by large-scale features of the circulation (e.g. extensive surface depressions), which basically act to provide the appropriate low-level moist flow relative to the topography, have greater predictabilities than those other situations where the responsible disturbance is smaller and faster evolving (e.g. a transient mesoscale size low pressure centre). In the present paper we explore this idea using the HYDROPTIMET flash flood events.

Interestingly, the HYDROPTIMET events (already described elsewhere in this special issue of NHESS) comprise different geographical zones (Catalogne, southern France and Piémont areas) and still more important, were regulated by both synoptic-scale and mesoscale disturbances depending on the case. In particular, we will analyse the so-called Catalogne event (9-10 June 2000), the Cévennes event (89 September 2002) and one of the two Piémont events of the project (24-26 November 2002). It will become evident when presenting the control simulations of the three cases (Sect. 2.1) that the first one was dominated by a mesoscale cyclogenesis along the northeast coast of Spain, the second one occurred under the influence of a southerly LLJ due to a large Atlantic low pressure area, and the last one combined large-scale properties of the responsible circulation during its first phase (Piémont-I) with the crucial role of a local cyclone developed over the western Mediterranean during the second phase of the episode (Piémont-II). Thus, the selected HYDROPTIMET events become an ideal set of situations to investigate the predictability issue as function of the spatial scale of the responsible circulation. Being aware that only four cases are not enough to draw general conclusions, at least some basic hypothesis on the predictability of prototype flash flood situations in the western Mediterranean will become apparent from the obtained results.

A key and unique aspect of the study is the methodology followed to analyse the predictability of the case studies. It is based on a small ensemble of perturbed MM5 
numerical simulations constructed by means of a potential vorticity (PV) inversion technique and supplementary information provided by the MM5 adjoint model. A full section is devoted to explain the details of the followed methodology and also to present the reference or control simulations of the events (Sect. 2). In Sect. 3 the outputs of the perturbed numerical simulations are compared against the control simulation for each event and the results are discussed in terms of the predictability offered by each of the flash flood situations. Finally,Sect. 4 includes the main conclusions arisen from the study.

\section{Methodology and control simulations}

One way of examining the predictability of a meteorological pattern by means of a numerical model consists of perturbing the model initial conditions and display the spread of the model forecasts, including as reference some control or standard forecast. Essentially, a sensitivity analysis of the model output trajectory. Here we are assuming that a major source of uncertainty in real-time forecasting is associated with a deficient knowledge of the initial conditions ingested in the mesoscale model, either because of insufficient observational data (a real problem in the data void Mediterranean latitudes) or as a result of using an already imperfect lower-resolution model forecast to construct the initial conditions, or both. We are not dealing in this methodology with the uncertainties of the mesoscale model itself arisen from the numerical discretisation and the representation of the physical processes. This exercise is also much simpler than standard ways of generating a representative collection of members in EPS systems. We will indeed examine the sensitivity of flash flood simulations to systematic perturbations of the upper-level precursor synoptic-scale trough, a feature of the flow emphasized in the control simulations shown in Sect. 2.1. Since these perturbations, expressed in terms of the potential vorticity, will be arbitrarily defined without regard to the actual climatology of analysis error variance of the PV field, our experiments will provide a sensitivity analysis of the events rather than a test of operational ensemble generation techniques, which should be designed in terms of the actual PV uncertainty.

Many studies have analysed the sensitivity of numerical forecasts to different physical factors. Boundary factors (e.g. orography, model boundary conditions and surface fluxes of energy and momentum) or factors involved in the model physical parameterizations (e.g. latent heat release in cloud masses and other microphysical processes) have been often considered. Much less attention has been paid to the effects of internal features of the flow dynamics (jet streaks, troughs, fronts, etc.). The three dimensional nature and mutual dependence of pressure, temperature and wind fields pose serious constraints on the ways these fields can be altered without altering the delicate dynamical balances that govern both the model equations and actual data. Since we intend to perturb the structure of an upper-level trough, the powerful concept of potential vorticity and its invertibility principle (Hoskins et al., 1985) will be used to prevent artificial unbalances in the modified initial conditions. According to the invertibility principle, given some balanced flow constraints and proper boundary conditions for the meteorological fields (pressure, temperature and wind), the knowledge of the three-dimensional distribution of PV can be used to infer the balanced meteorological fields. Application of piecewise $\mathrm{PV}$ inversion is particularly useful and a clean approach to manipulate the upper-level troughs in the present study. What it is necessary is a simple identification of the PV signature of each trough and then the mass and wind fields associated with that PV element can be used to alter the meteorological fields in a physically consistent way (effectively, a change in the structure or position of the trough). Several studies have applied piecewise PV inversion methods to investigate the role of dynamical features of the flow, particularly for cyclogenesis events (e.g. Davis, 1992; Hakim et al., 1996; Huo et al., 1999; Morgan, 1999; Fehlmann et al., 2000; Romero, 2001; Homar et al., 2002). The specific piecewise PV inversion scheme employed in this study is described in Sect. 2.2.

The previous approach is used for the four flash flood events to generate an ensemble of mesoscale numerical simulations with perturbed initial intensities or positions of the upper-level trough PV signature. The PV-based approach is similar in the scope to more classical adjoint techniques used in ensemble forecasting (e.g. Petroliagis et al., 1996). However, they differ substantially from a methodological point of view, since we define the perturbations based on selected finite-amplitude physical attributes of the precursor upperlevel disturbance but these features are not necessarily the most unstable aspects of the flow that an adjoint/singular vector method would seek to determine. To mitigate the arbitrariness that is involved in the definition of the perturbations, we first applied an adjoint model to locate the main sensitivity areas at simulation start time. The adjoint model consistently exhibited high sensitivities of the flash flood local environments within and around the upper-level trough (see Sect. 2.3), and therefore our choice of manipulating that trough for generating the perturbed simulations appears to be justified.

\subsection{MM5 model and control simulations}

The numerical experiments were performed using the fifth generation of the Pennsylvania State University-National Center for Atmospheric Research mesoscale model (MM5; Dudhia, 1993; Grell et al., 1995). The MM5 is a full nonhydrostatic model formulated using the terrain-following $\sigma$ coordinate system in the vertical. The multiple-nest capability of the model with two-way interaction between successive nesting levels was used in order to get realistic terrain features and explicit representation of mesoscale processes (Zhang et al., 1986).

For the present simulations, two interacting domains under a Lambert conformal map projection were used, both of them with $81 \times 81 \times 24$ grid points. The fine domain measures 
$1458 \mathrm{~km} \times 1458 \mathrm{~km}$ (grid length $18 \mathrm{~km}$ ) and the coarse domain $4374 \mathrm{~km} \times 4374 \mathrm{~km}$ (grid length $54 \mathrm{~km}$ ). Both domains are centred at the region affected by the flash floods (Figs. 1 to 8). Time steps for model integration were $54 \mathrm{~s}$ and $162 \mathrm{~s}$, respectively. Global analyses on standard pressure surfaces from NCEP (available at 00:00 and 12:00 UTC with $2.5^{0}$ horizontal resolution) and ECMWF (at 00:00, 06:00, 12:00 and 18:00 UTC with $0.3^{0}$ resolution) were available to nest the mesoscale model. It was decided to check a control simulation performed with each data set and use for the study the analyses that offered the best results in terms of precipitation forecasts. Accordingly, initial and boundary conditions for the coarse domain were constructed from the global analyses from NCEP for Catalogne and Cévennes events, and from ECMWF for Piémont-I and Piémont-II events. In all cases the reanalyses on the MM5 model grid were improved using surface and upper-air observations with a successivecorrection objective analysis technique (Benjamin and Seaman, 1985). The tendencies along the model coarse domain boundaries, specified by differences of the fields between the $12 \mathrm{~h}$ and $6 \mathrm{~h}$ apart analyses, respectively, were applied using a Newtonian relaxation approach (Grell et al., 1995).

The MM5 model includes different options for the physical parameterizations. For the present study, the parameterization scheme used to represent the planetary boundary layer physics was a modified version of the Hong and Pan scheme (Hong and Pan, 1996). It includes an implicit vertical diffusion scheme, assuming a $k$-profile, which uses a countergradient equation. Surface temperature over land was calculated using a force-restore slab model (Blackadar, 1979; Zhang and Anthes, 1982), and over sea it remained constant during the simulations. Surface fluxes, as well as atmospheric temperature tendencies caused by longwave and shortwave radiation components, were calculated taking into account the cloud cover (Benjamin, 1983). Explicit microphysics was represented with prediction equations for cloud and rain water fields, cloud ice and snow allowing for slow melting of snow, supercooled water, graupel and ice number concentration (Reisner et al., 1998). The Kain and Fritsch parameterization scheme (Kain and Fritsch, 1990) was used to calculate moist convection effects.

Simulations extend $36 \mathrm{~h}$ for Catalogne (from 00:00 UTC 9 June 2000 to 12:00 UTC 10 June 2000), $54 \mathrm{~h}$ for Cévennes (00:00 UTC 8 September 2002-06:00 UTC 10 September 2002), 36 h for Piémont-I (00:00 UTC 24 November 200212:00 UTC 25 November 2002), and $36 \mathrm{~h}$ for Piémont-II (00:00 UTC 25 November 2002-12:00 UTC 26 November 2002). The control simulations can be used to identify the main synoptic and mesoscale structures responsible for the flash-flood environments and to assess the model capability for forecasting spatial and quantitative details of the precipitation field. Additional experiments without orography and evaporation from the Mediterranean (not included) were also performed to reinforce some of the following interpretations.

\subsubsection{Catalogne event}

Results for the Catalogne event are summarized in Figs. 1 and 2. This event was associated with a relatively small scale baroclinic development. The synoptic situation at the initial time exhibits an intense cold trough and the corresponding positive PV anomaly northwest of the Iberian Peninsula at mid-tropospheric levels (Fig. 1a). This trough had a relatively short wavelength and evolved very rapidly towards the eastern coast of Spain, such that its meridionally oriented initial axis became negatively tilted by the time of the convective developments over Catalogne (Fig. 1b). In response to the strong vorticity advection occurring aloft over eastern Spain as the intense trough entered the Peninsula and given the remarkable baroclinicity of the flow (note the thermal gradient in Figs. 1c and d), a mesoscale size cyclone developed near the eastern coast of Spain (see Fig. 1d). A nonorographic simulation of this event (not shown) confirms that a significant part of that cyclogenesis was due to the Iberian topography and particularly to the Pyrenees mountain range, which acted focusing and anchoring the low pressure system to its south. This cyclone exerted a major control of the flash flood event over Catalogne. It supplied warm and moist Mediterranean air at low levels over the region, which combined with the intrusion of cold air at upper levels to increase the convective instability of the environment. In fact, low level convergence in Catalonia during the first hours of 10 June was enhanced by the combination of three distinct airstreams: the abovementioned warm and moist southeasterly flow, a cold flow turning anticyclonically around the eastern tip of the Pyrenees, and the NW winds associated with the approaching cold front (Fig. 2a). Moreover, the impinging flow against the pre-littoral mountains of Catalogne, attributed to the cyclone, was a key factor for releasing the convective instability. In fact, the maximum rainfall was observed over the interior mountains of Catalogne (Fig. 2b). Comparing the observed rainfall distribution with the simulated one (Fig. 2a), it can be concluded that the MM5 model simulates accurately the synoptic and mesoscale processes since the forecast rainfall is reasonably good, both spatially and quantitatively. This control experiment also suggests that an incorrect prediction of the surface cyclone in terms of its genesis area, trajectory or speed, would negatively affect the rainfall forecast over Catalogne, since the previous characteristics of the low-level flow relative to the affected area would appreciably change owing to the small dimensions of the cyclone. In fact, the end of the flash flood event was due to a change of the low-level flow over Catalogne into cold, drier northwesterly winds as the cyclone progressed further northeastward into southern France, following the evolution of the upper-level trough (not shown).

\subsubsection{Cévennes event}

The synoptic setting of the Cévennes event was also characterized by a large-scale trough at mid-upper tropospheric levels, although it was wider than in the previous case and 

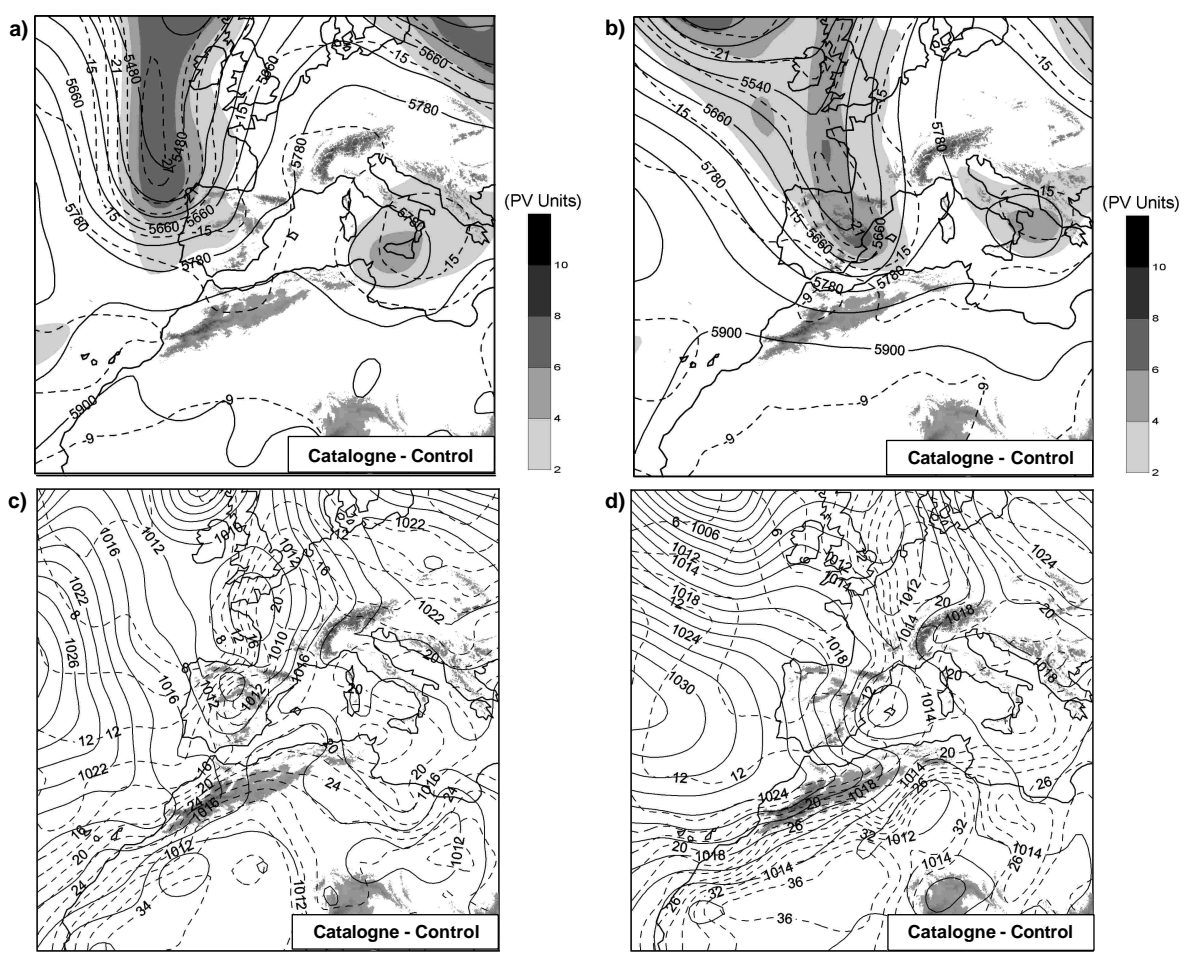

Fig. 1. Control simulation of the Catalogne event for the coarse domain, showing geopotential height at $500 \mathrm{hPa}$ (continuous line, in gpm), temperature at $500 \mathrm{hPa}$ (dashed line, in ${ }^{\circ} \mathrm{C}$ ) and isentropic PV on the $330 \mathrm{~K}$ surface (shaded, according to scale) at (a) 00:00 UTC 9 June 2000 and (b) 00:00 UTC 10 June 2000; sea level pressure (continuous line, in hPa) and temperature at $950 \mathrm{hPa}\left(\mathrm{dashed}\right.$ line, in $\left.{ }^{\circ} \mathrm{C}\right)$ at $(\mathbf{c})$ 00:00 UTC 9 June 2000 and (d) 00:00 UTC 10 June 2000. Main orographic systems are highlighted.

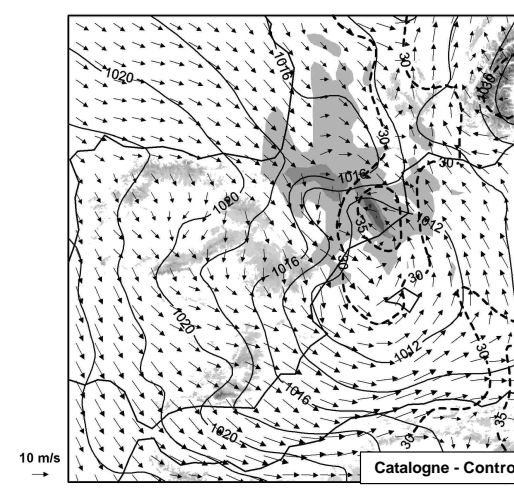

a)

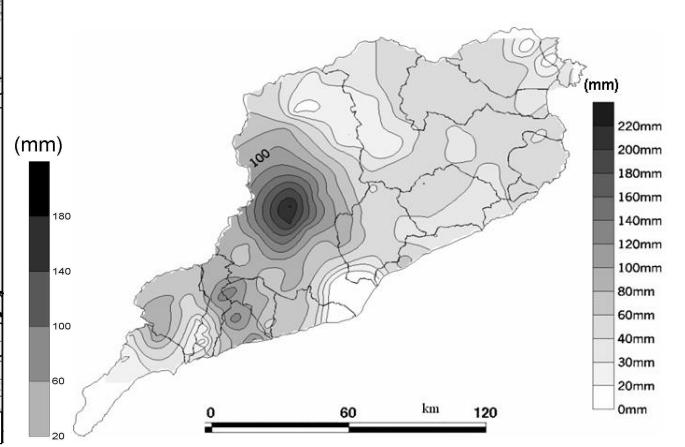

b)

Fig. 2. (a) Control simulation of the Catalogne event for the fine domain, showing sea level pressure (continuous line, in hPa), precipitable water (dashed line, in $\mathrm{mm}$ ) and horizontal wind at $950 \mathrm{hPa}$ (vectors) at 00:00 UTC 10 June 2000, and accumulated rainfall at the end of the simulation (shaded according to scale, with a maximum value of $165 \mathrm{~mm}$ ); (b) Rain gauge derived precipitation in eastern Catalogne, accumulated from 00:00 UTC 9 June to 12:00 UTC 10 June 2000 (courtesy of M. C. Llasat). Main orographic systems are highlighted in (a).

located during the full episode over the Atlantic Ocean, far from the affected area in southern France (Figs. 3a and b). This trough and the corresponding positive PV anomaly tilted negatively during the episode as in the Catalogne case, but the nature of the surface circulation responsible for the flash flood producing convective system was remarkably different. In first place, the surface cyclone was much larger (synoptic scale vs. mesoscale dimensions). In second place, it was not located over the Mediterranean basin but over Atlantic, far from the affected area (Figs. 3c and d). However, it provided and essential component for the genesis and maintenance of the quasistationary convective system that affected during many hours the Cévennes region: a southerly low-level jet over the western Mediterranean impinging over the topography of southern France (Fig. 3d). This LLJ occurred ahead of the surface cyclone and associated cold front 

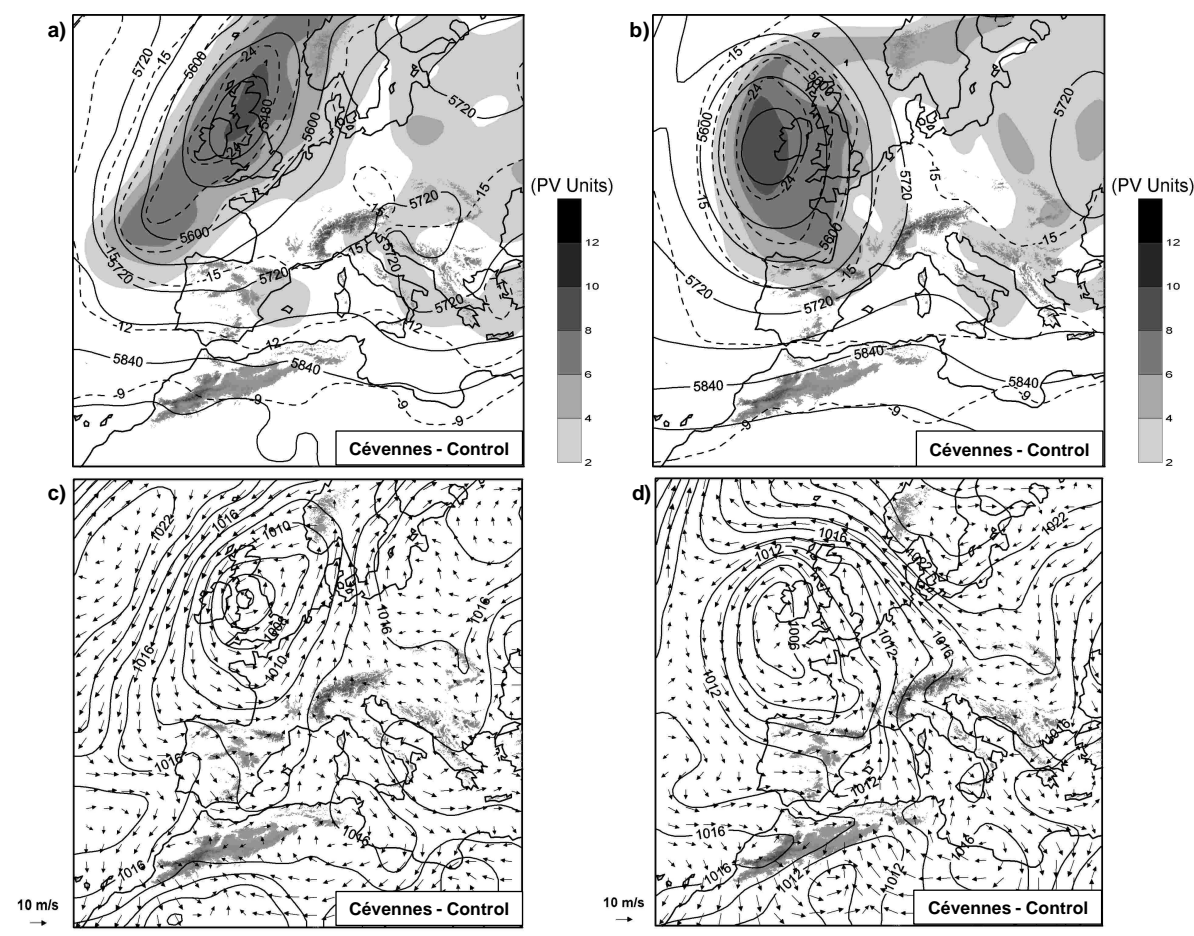

Fig. 3. Control simulation of the Cévennes event for the coarse domain, showing the same fields as in Fig. 1 except that the horizontal wind at $950 \mathrm{hPa}$ (vectors) is shown in (c) and (d) instead of the temperature field. The fields are shown at 00:00 UTC 8 September 2002 in (a) and (c), and 00:00 UTC 9 September 2002 in (b) and (d).

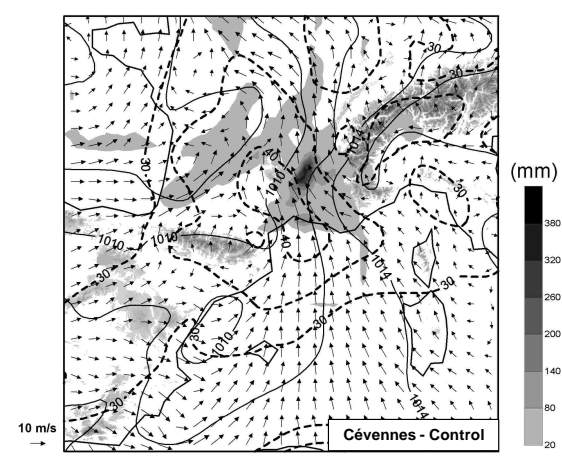

a)

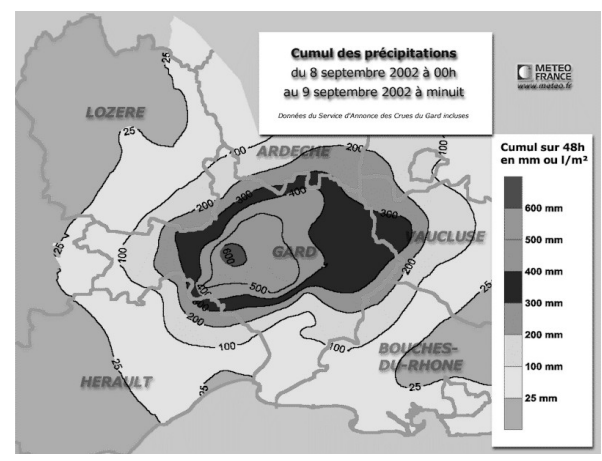

b)

Fig. 4. (a) Control simulation of the Cévennes event for the fine domain, showing the same fields as in Fig. 2a but at 00:00 UTC 9 September 2002 (accumulated rainfall corresponds to the end of the simulation, with a maximum value of $367 \mathrm{~mm}$ ); (b) Rain gauge derived precipitation in the Cévennes region, accumulated during the period indicated in the figure (courtesy of Meteo France).

(the frontal trough is clearly visible off the eastern coast of Spain in Fig. 3d), and brought warm and moist air towards southern France during many hours. A key feature of the episode was the relative stagnancy of the synoptic situation, which allowed a long persistence of the LLJ and therefore the generation of convective instability and moisture flux convergence in the convective zone for a long time. This explains the long-lasting and quasistationary character of both the simulated and observed rainfall during the event (accumulated values are shown in Fig. 4). Comparing Figs. 4a and $4 \mathrm{~b}$ it can be concluded that the control simulation is reason- ably good in this case as well, except that the model tends to locate the precipitation centre about the inland mountain slopes rather than over the low-land areas where it was actually observed. Such misplacement has been observed in all other standard simulations of the event performed by other partners of HYDROPTIMET, and it is only corrected by means of mesoscale data assimilation schemes (see Ducrocq et al., 2004). From the low-level flow depicted in Fig. $4 \mathrm{~b}$ it can be appreciated, moreover, the notable role of the Alps mountains in the sense of enhancing along its western flank the abovementioned LLJ. Given the large scale nature and 
quasistationary character of the processes involved in the Cévennes episode compared to Catalogne, it can be anticipated that uncertainties in the upper-level precursor disturbance should not affect drastically the predictability of the event.

\subsubsection{Piémont-I event}

The Piémont-I event shares many aspects of the Cévennes episode attending to the relevant synoptic and mesoscale processes. The event was also linked to an upper-level system of long wavelength with the trough located over the Atlantic Ocean (Figs. 5a and 5b). However, unlike the Cévennes situation which evolved to a cutoff-low pattern (recall Fig. 3b), in this case the trough maintained an open wave pattern and the accompanying PV anomaly did not become isolated from the high-latitude reservoir (Fig. 5b). At low levels the situation resembles again the Cévennes situation in that the low-level circulation was also regulated by an extensive low-pressure area lying over the Atlantic which induced a southerly LLJ with a long fetch over the Mediterranean that impinged over the Alpine region. These features can be appreciated on Figs. 5c and 5d, but in comparison with Figs. $3 \mathrm{c}$ and $3 \mathrm{~d}$ it can be observed a more evident secondary trough/cyclone about the Iberian Peninsula which helped to enhance the LLJ towards the end of the period. A similar function than in the previous event can be attributed to this LLJ, in the sense of supplying moisture rich air from the Mediterranean into the affected area and forcing upward vertical motion through mechanical lifting over the slopes of the Alps and its foothills. These processes are essentially well captured by the MM5 model since the forecast rainfall (Fig. 6a) reproduces many qualitative and quantitative aspects of the observed precipitation (Figs. 6b, c and d). The precipitation forecast is particularly good inland, over the slopes of the Alps, as a clear example of the predictability level added by the strong topographic forcing. It is unclear, however, what is the effect on the predictability of perturbing the upper-level disturbance. A priori, it could be expected also in this case a relatively high predictability given the large-scale nature of key processes operating in the event.

\subsubsection{Piémont-II event}

It is interesting the transition observed during the long Piémont episode towards its second phase. The results of the control experiment of Piémont-II are shown in Figs. 7 and 8. As the upper-level trough intensified and advanced eastward into North Africa and the western Mediterranean (Figs. 7a and b), cyclogenesis occurred at surface over the western Mediterranean basin (Figs. 7c and d). [The resulting cyclone can be classified as of mesoscale size, although it is much larger than the cyclone developed in the Catalogne event (compare with Fig. 1d)]. The meridionally elongated mesoscale cyclone conditioned the direction and strength of the moist LLJ along its eastern flank. Specifically, while the cyclone moved farther east and tilted negatively, the LLJ lost entity over the north Mediterranean coast and veered to a south-easterly direction. By the end of the simulation period the wind over the Piémont region is not longer onshore, but rather from the east (evolution not shown). This fact motivated the cessation of the heavy precipitations over the region. Therefore, it is again interesting to examine to which extent possible errors in the representation of the initial upper-level trough would affect the heavy precipitation forecast, owing to a deficient prediction of the surface cyclone characteristics. Consideration of this control simulation as a reference point appears to be appropriate attending to the good skill of the model to simulate many aspects of the precipitation field (Fig. 8).

\subsection{Piecewise PV Inversion Scheme}

The method used to investigate the sensitivity of the mesoscale simulations to changes in the upper-level precursor trough requires the calculation of a balanced flow associated with the trough-related PV anomaly at simulation start time. For that purpose the piecewise PV inversion technique of Davis and Emanuel (1991) was used. The method begins with the calculation of the total balance flow, described by $\phi$ (geopotential) and $\psi$ (streamfunction), from the instantaneous distribution of Ertel's potential vorticity $(q)$, defined as:

$q=\frac{1}{\rho} \boldsymbol{\eta} \cdot \nabla \theta$,

where $\rho$ is the density, $\boldsymbol{\eta}$ is the absolute vorticity vector and $\theta$ is the potential temperature. The balance assumption made herein follows the Charney (1955) nonlinear balance equation:

$\nabla^{2} \phi=\nabla \cdot f \nabla \psi+2 m^{2}\left[\frac{\partial^{2} \psi}{\partial x^{2}} \frac{\partial^{2} \psi}{\partial^{2} y}-\left(\frac{\partial^{2} \psi}{\partial x \partial y}\right)^{2}\right]$

where $f$ is the Coriolis parameter and $m$ is the map-scale factor of the Lambert conformal projection $(x, y)$ used to define the model domain. The other diagnostic relation necessary for the inversion of $\phi$ and $\psi$ is given by an approximate form of Eq. (1) resulting from the hydrostatic condition and the same scale analysis used to derive (2), namely, that the irrotational component of the wind is negligible against the non-divergent wind:

$$
\begin{aligned}
q & =\frac{g \kappa \pi}{p}\left[\left(f+m^{2} \nabla^{2} \psi\right) \frac{\partial^{2} \phi}{\partial^{2} \pi}\right. \\
& \left.-m^{2}\left(\frac{\partial^{2} \psi}{\partial x \partial \pi} \frac{\partial^{2} \phi}{\partial x \partial \pi}+\frac{\partial^{2} \psi}{\partial y \partial \pi} \frac{\partial^{2} \phi}{\partial y \partial \pi}\right)\right]
\end{aligned}
$$

where $p$ is the pressure, $g$ is the gravity, $k=R_{d} / C_{p}$ and the vertical coordinate $\pi$ is the Exner function $C_{p}\left(p / p_{0}\right)^{k}$

Given $q$, the finite-difference form of the closed system described by Eqs. (2) and (3) is solved for the unknown $\phi$ and $\psi$, using an iterative technique until convergence of the solutions is attained (refer to Davis and 

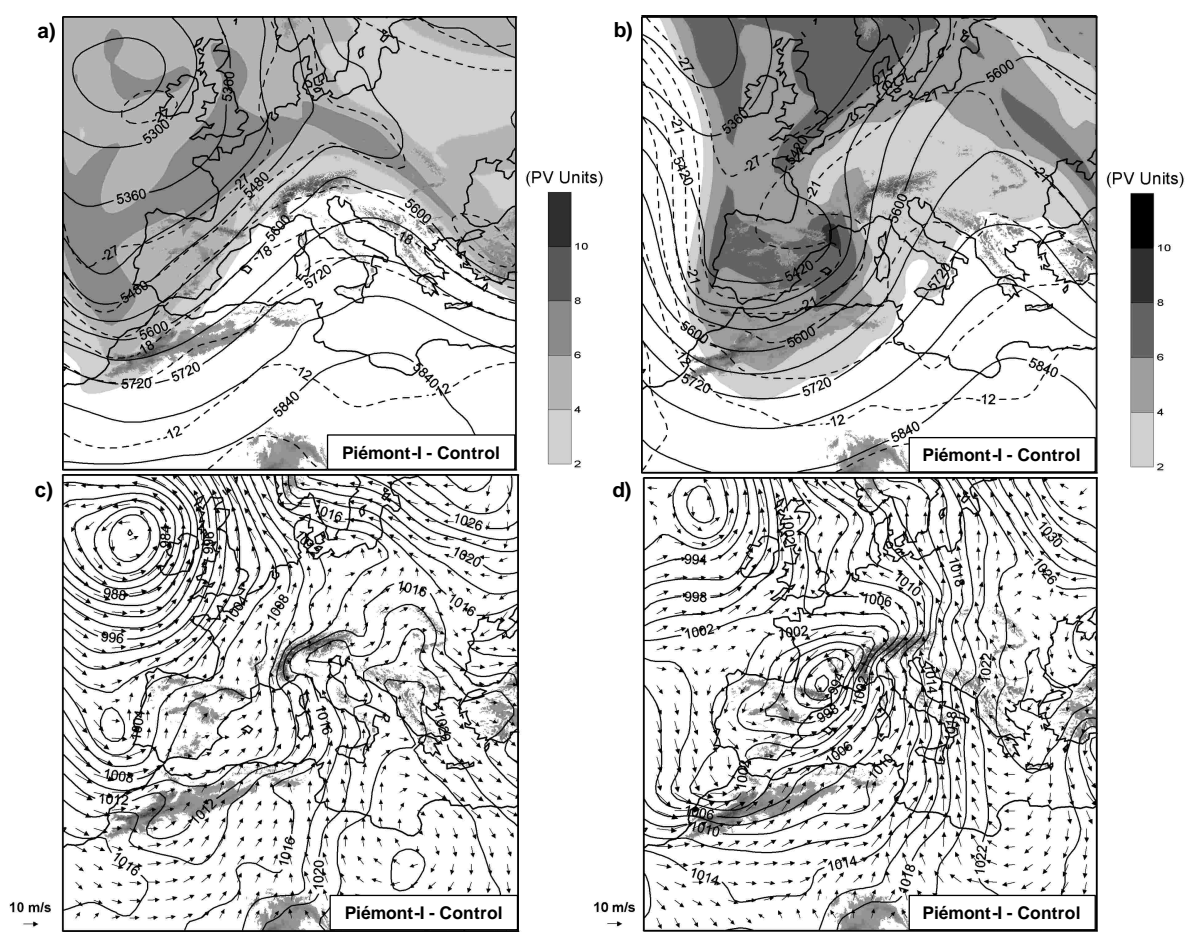

Fig. 5. Control simulation of the Piémont-I event for the fine domain, showing the same fields as in Fig. 1 except that the horizontal wind at $950 \mathrm{hPa}$ (vectors) is shown in (c) and (d) instead of the temperature field. The fields are shown at 00:00 UTC 24 November 2002 in (a) and (c), and 00:00 UTC 25 November 2002 in (b) and (d).
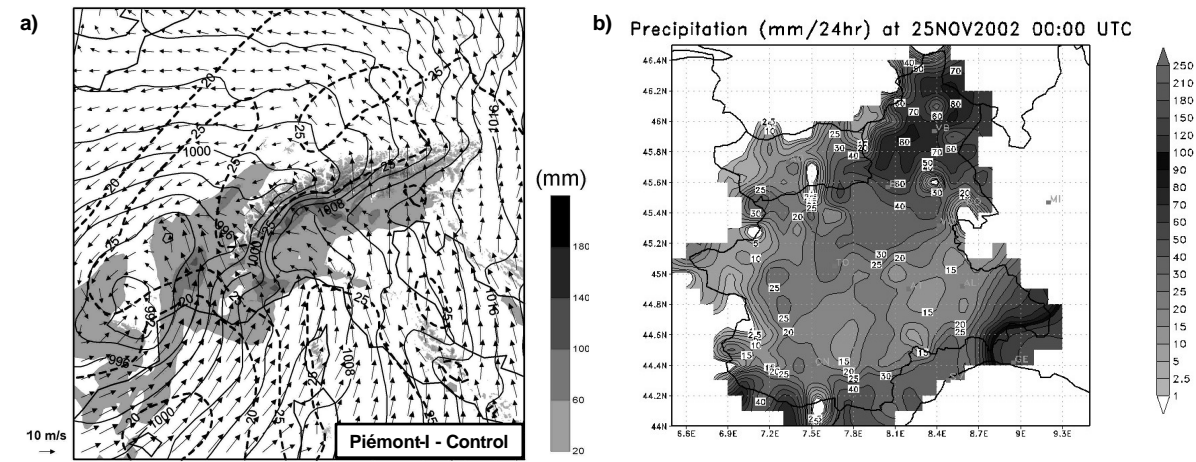

c)
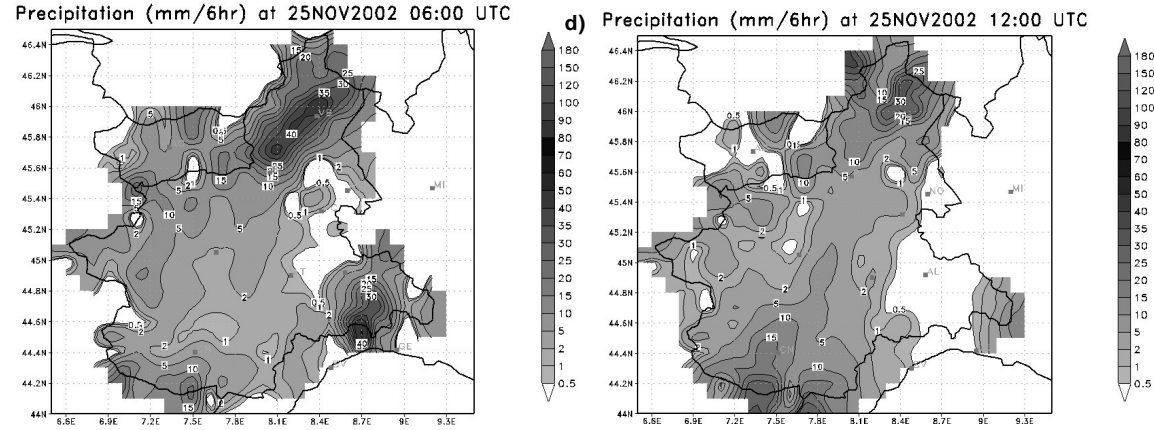

Fig. 6. (a) Control simulation of the Piémont-I event for the fine domain, showing the same fields as in Fig. 2a but at 00:00 UTC 25 November 2002 (accumulated rainfall corresponds to the end of the simulation, with a maximum value of $157 \mathrm{~mm}$ ); (b), (c) and (d) Rain gauge derived precipitation in the Piémont region, accumulated during the periods indicated (courtesy of M. Milelli). 

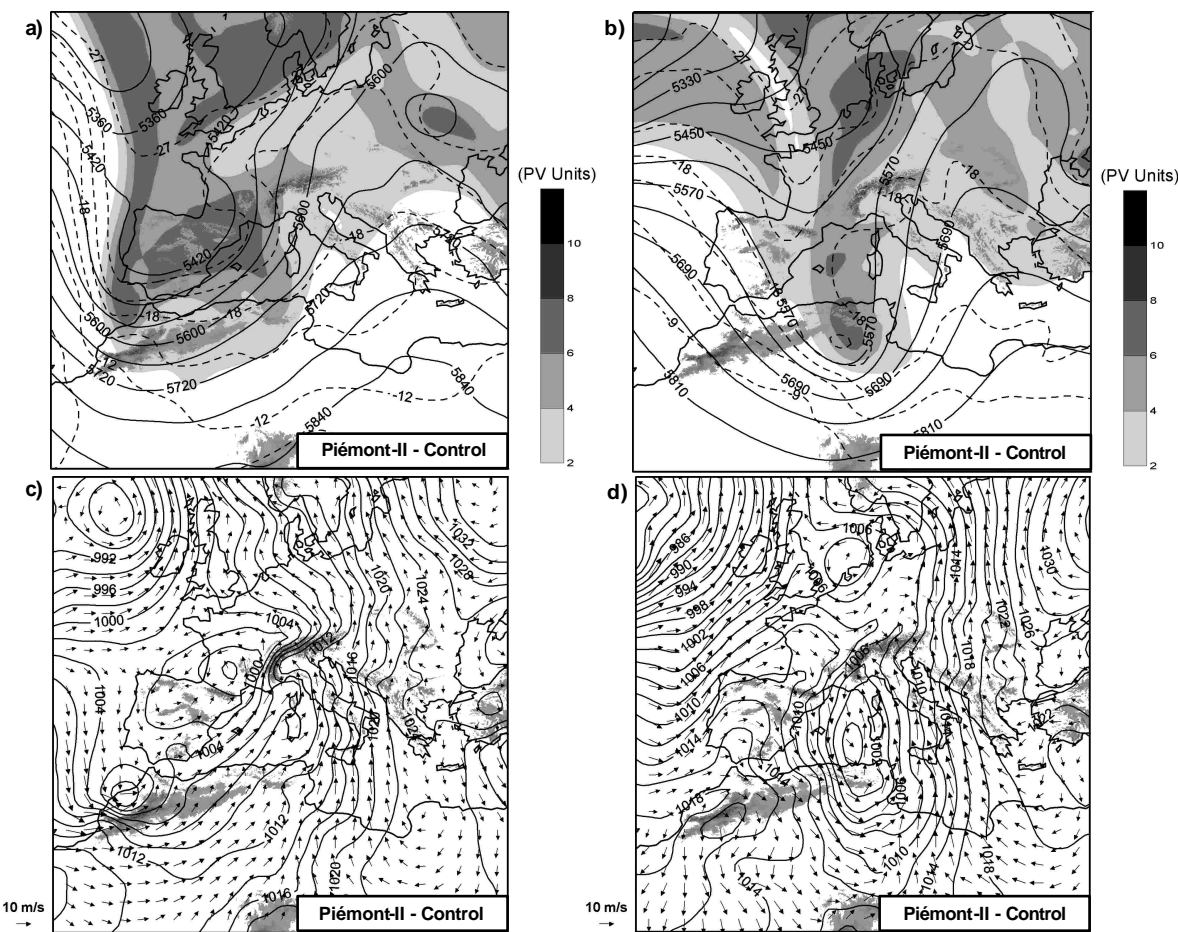

Fig. 7. Control simulation of the Piémont-II event for the coarse domain, showing the same fields as in Fig. 1 except that the horizontal wind at $950 \mathrm{hPa}$ (vectors) is shown in (c) and (d) instead of the temperature field. The fields are shown at 00:00 UTC 25 November 2002 in (a) and (c), and 00:00 UTC 26 November 2002 in (b) and (d).

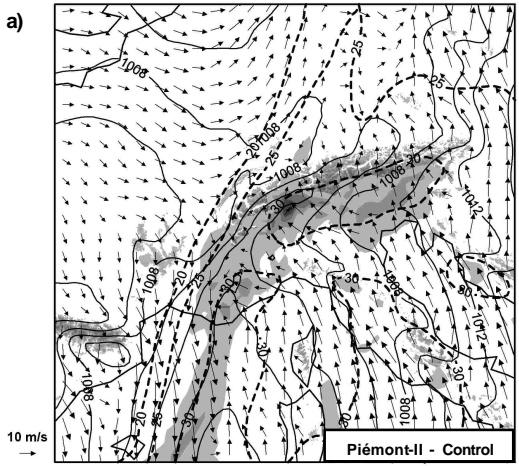

c)

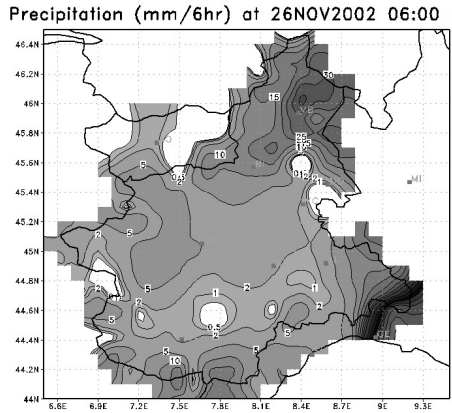

b) Precipitation ( $\mathrm{mm} / 24 \mathrm{hr}$ ) at $26 \mathrm{NOV} 2002$ 00:00 UTC

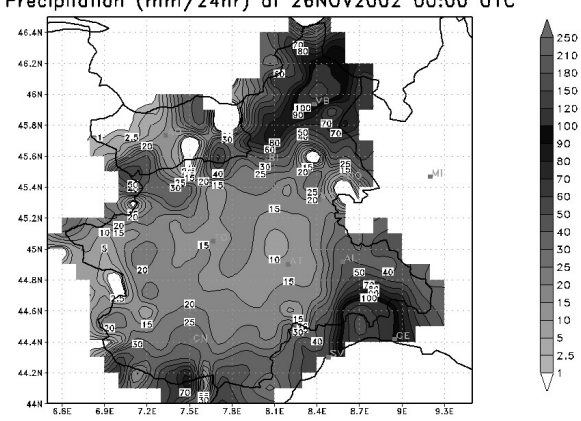

d)

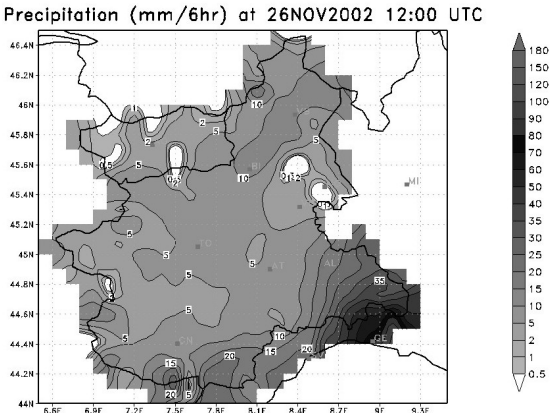

Fig. 8. (a) Control simulation of the Piémont-II event for the fine domain, showing the same fields as in Fig. 2 a but at 00:00 UTC 26 November 2002 (accumulated rainfall corresponds to the end of the simulation, with a maximum value of $223 \mathrm{~mm}$ ); (b), (c) and (d) Rain gauge derived precipitation in the Piémont region, accumulated during the periods indicated (courtesy of M. Milelli). 
Emanuel, 1991 for details). Neumann type boundary conditions $(\partial \phi / \partial \pi=f \partial \psi / \partial \pi=-\theta)$ are applied at the top and bottom boundaries, and Dirichlet conditions at the lateral boundaries. The later are supplied by the observed geopotential and a streamfunction calculated by matching its gradient along the edge of each isobaric surface to the observed normal wind component, which is first slightly modified to force no net divergence in the domain. Owing to the balance condition used, the inverted fields are very accurate even for meteorological systems characterised by large Rossby numbers (Davis and Emanuel, 1991; Davis, 1992).

Later, a reference state must be found from which to define the PV anomalies. As in Davis and Emanuel (1991), this reference state is defined as a time average. Given $\bar{q}$ (the time mean of $q$ ), a balanced mean flow $(\bar{\phi}, \bar{\psi})$ is inverted from identical equations to (2) and (3), except all dependent variables are mean values and the mean potential temperature, $\theta$, is used for the top and bottom boundary conditions. The total fields will differ from the time averages by the perturbations $\left(q^{\prime}, \phi^{\prime}, \psi^{\prime}\right)$ :

$(q, \phi, \psi)=(\bar{q}, \bar{\phi}, \bar{\psi})+\left(q^{\prime}, \phi^{\prime}, \psi^{\prime}\right)$.

The PV perturbation field $q^{\prime}$ can be considered as a partition of $N$ portions or anomalies, $q^{\prime}=\sum_{n=1}^{N} q_{n}$. The piecewise inversion scheme determines that part of the balance flow $\phi_{n}, \psi_{n}$ associated to each PV portion $q_{n}$, requiring in that process that $\phi^{\prime}=\sum_{n=1}^{N} \phi_{n}$ and $\psi^{\prime}=\sum_{n=1}^{N} \psi_{n}$. As discussed in Davis (1992), there is no unique way to define a relationship between $\left(\phi_{n}, \psi_{n}\right)$ and $q_{n}$ owing to the nonlinearities present in Eqs. (2) and (3). The linear method of Davis and Emanuel (1991) is here adopted, obtained after substituting Eq. (4) and the above summations in Eqs. (2) and (3) and equal partitioning of the nonlinear term among the other two linear terms that result from each nonlinearity in the above equations (see Davis and Emanuel, 1991 for the details). The resulting closed linear system for the $n^{\text {th }}$ perturbation is:

$$
\begin{aligned}
\nabla^{2} \phi_{n} & =\nabla \cdot f \nabla \psi_{n} \\
& +2 m^{2}\left(\frac{\partial^{2} \psi^{*}}{\partial x^{2}} \frac{\partial^{2} \psi_{n}}{\partial y^{2}}+\frac{\partial^{2} \psi^{*}}{\partial y^{2}} \frac{\partial^{2} \psi_{n}}{\partial x^{2}}\right. \\
& \left.-2 \frac{\partial^{2} \psi^{*}}{\partial x \partial y} \frac{\partial^{2} \psi_{n}}{\partial y \partial x}\right)
\end{aligned}
$$

$$
\begin{aligned}
q_{n} & =\frac{g \kappa \pi}{p}\left[\left(f+m^{2} \nabla^{2} \psi^{*}\right) \frac{\partial^{2} \phi_{n}}{\partial \pi^{2}}+m^{2} \frac{\partial^{2} \phi^{*}}{\partial \pi^{2}} \nabla^{2} \psi_{n}\right. \\
& -m^{2}\left(\frac{\partial^{2} \phi^{*}}{\partial x \partial \pi} \frac{\partial^{2} \phi^{*}}{\partial x \partial \pi}+\frac{\partial^{2} \psi_{n}}{\partial y \partial \pi} \frac{\partial^{2} \psi_{n}}{\partial y \partial \pi}\right) \\
& \left.-m^{2}\left(\frac{\partial^{2} \psi^{*}}{\partial x \partial \pi} \frac{\partial^{2} \phi_{n}}{\partial x \partial \pi}+\frac{\partial^{2} \psi^{*}}{\partial y \partial \pi} \frac{\partial^{2} \phi_{n}}{\partial y \partial \pi}\right)\right]
\end{aligned}
$$

where ()$^{*}=\overline{()}+\frac{1}{2}()^{\prime}$
The system (Eqs. 5-6) was solved for the PV anomalies identified above $500 \mathrm{hPa}$ in relation with the upper-level synoptic troughs governing the flash-flood events, using homogeneous boundary conditions for $\phi_{n}$ and $\psi_{n}$ at the top, bottom and lateral boundaries. The shapes of these positive PV anomalies on the $330 \mathrm{~K}$ isentropic surface are displayed in Fig. 9. In all cases the southern tip of the troughs is captured in the selected PV signature. The balance flow $\left(\phi_{n}, \psi_{n}\right)$ associated with the anomalies can then be used to alter the model initial conditions without introducing any significant unbalance to the fields.

\subsection{Adjoint method and sensitivity fields}

The PV inversion technique attributes components of the mass and wind fields to structures of the PV field. This allows exploring the impact of PV features in the initial conditions on the evolution of numerical simulations. Within this framework, a linear adjoint model is a powerful tool that can provide direct guidance about the PV features that are most likely influential for a particular aspect of interest in the forecast (Arbogast, 1998). A usual application of adjoint models is to compute sensitivities of forecast errors and detect regions in the initial conditions that are most likely responsible for the errors (e.g. Errico, 1997). Here, the results of an adjoint model provide guidance to define initial perturbations where the four episodes analysed show large sensitivity and therefore where small errors would lead to major errors in the forecast of the damaging rains, reducing its predictability. In order to confirm the applicability of the tangent linear approximation under the perturbations defined for the four episodes, we tested that symmetric perturbations to the initial conditions produce changes in the MM5 forecast fields of interest that are largely symmetric.

We use the MM5 Adjoint model (Zou et al., 1997, 1998) developed at NCAR, which has already been applied and tested for a Mediterranean intense cyclone by Homar and Stensrud (2004). The adjoint model includes a limited number of physical parameterization scheme options that, together with the intrinsic tangent-linear approximation, limits the value of its results in the standard nonlinear context. As a result, using the adjoint system requires a thoughtful set up of the runs, a test of the linear approximation and a careful interpretation of the resulting sensitivities. The sensitivity calculations are run on the mother domain of each control experiment for the three episodes. Moist processes are considered in the adjoint integration. The explicit moisture, including ice concentration is parameterized using the adjoint of the Dudhia (1989) microphysics scheme and the Grell et al. (1995) convective scheme is also included. No boundary layer parameterization is available but radiation and surface fluxes are considered. Using this configuration, we provide the model a response function of interest at a certain sensitivity time and it traces back its sensitivity to the initial conditions fields. In its current version, the model code does not allow defining response functions based on fields other than the wind speed, temperature, pressure and specific humidity. 

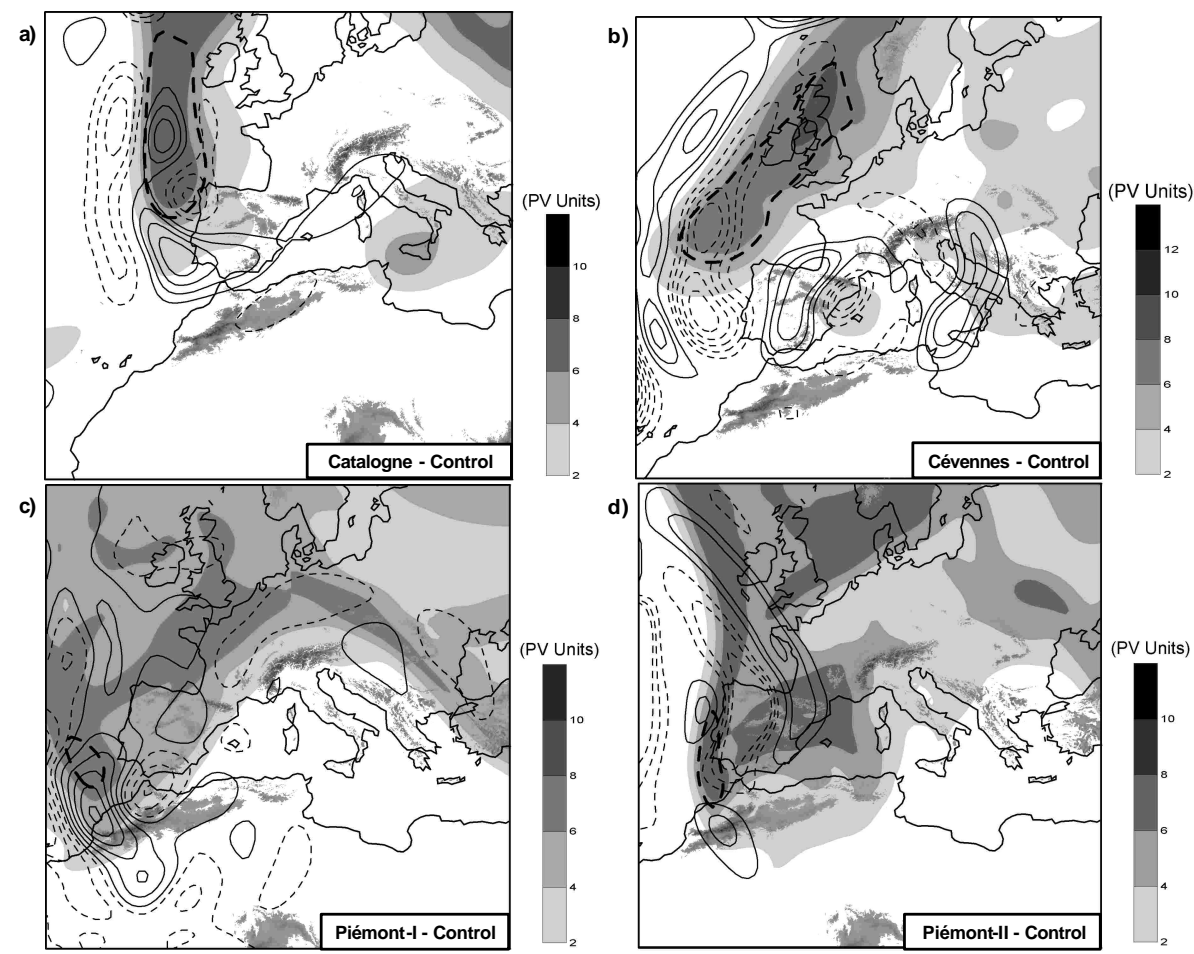

Fig. 9. Isentropic PV on the $330 \mathrm{~K}$ surface (shaded, according to scale) and main areas of sensitivity at the same isentropic surface (continuous line, positive values; dashed line, negative values) for the selected response functions (see text): (a) Catalogne event at 00:00 UTC 9 June 2000; (b) Cévennes event at 00:00 UTC 8 September 2002; (c) Piémont-I event at 00:00 UTC 24 November 2002; and (d) Piémont-II event at 00:00 UTC 25 November 2002. As thick dashed line, the PV anomaly that was inverted to construct the perturbed simulations is shown on the $330 \mathrm{~K}$ surface.

It is well known that small scale details of the sensitivity fields computed by the adjoint are very sensitive to the definition of the response function. Provided the limitations in the model code and in order to obtain representative results, it is preferred to define response functions that characterize precursor dynamical systems clearly linked to the feature of most interest in the forecast. For instance, convective rainfall is likely not well approximated by the tangent-linear models and the adjoint results are less accurate approximations to the actual sensitivities of the nonlinear standard run than those calculated from precursor dynamical systems. Here, we have defined the response functions for each case according to the low-level systems previously identified to be involved in triggering and sustaining the intense precipitations. For the Catalogne case, the vorticity over the center of the low-level cyclone developed offshore northeastern Spain is used as response function at 00:00 UTC 10 June 2000. The Cévennes case is driven by the low-level jet and so the response function definition is based on the low-level wind over the Gulf of Lyons and extending southeast, towards Sardinia at 06:00 UTC 9 September 2002. Finally, for the two active periods of the Piedmont episode the response functions are defined as the low-level wind on the eastern side of the cyclone at 06:00 UTC 25 November 2002 and the sealevel pressure around the cyclone center at 06:00 UTC 26 November 2002, respectively. The adjoint model is then ini- tialized with these response functions and their sensitivity to the corresponding initial conditions is computed.

The adjoint produces a sensitivity field for each of the model fields: temperature, horizontal wind components, pressure perturbation and specific humidity. Several methods aimed at summarizing the adjoint results into a single field are available. Arbogast (1998) presents a technique to compute sensitivities to a linearized version of the Ertel PV. Langland et al. (2002) define the response function based on energy and the adjoint results can be summarized in terms of a single energy field. Here we use the sensitivity to the Quasigeostrophic PV (QPV) to provide guidance to the aforementioned PV inversion technique. The quasigeostrophic PV field tends to mimic the position, alignment and gradients of the Ertel PV for the synoptic scale at mid-latitudes (Hakim et al., 1996). In the quasigeostrophic framework, PV is expressed as a funtion of the geostrophic stream function $(\Psi)$ as:

$q=\nabla_{p}^{2} \Psi+f_{0}+f_{0}^{2} \partial_{p}\left(\frac{1}{\sigma_{r}} \partial_{p} \Psi\right)$

where $q$ is the QPV, $\Psi$ the geostrophic streamfunction, $\sigma_{r}(p)$ the static stability parameter for a reference state, that depends only on $p$, and $f_{0}$ the Coriolis parameter, assumed constant over the domain. Transposing the discretized version of this equation, and using the relationship between the 
Table 1. Summary of the numerical experiments performed for the four flash-flood events according to the methodology described in the text. Note that the upper-level trough is displaced $270 \mathrm{~km}$ for Cévennes and $216 \mathrm{~km}$ for the rest of events.

\begin{tabular}{lccccc}
\hline & \multicolumn{5}{c}{ Type of perturbation of the upper-level trough } \\
\hline Event & Unchanged & Weakened 25\% & Intensified 25\% & Moved westward 200-300 km & Moved eastward 200-300 km \\
\hline Catalogne & Control & PV -25 & PV +25 & PV 216W & PV 216E \\
Cévennes & Control & PV -25 & PV +25 & PV 270W & PV 270E \\
Piémont-I & Control & PV -25 & PV +25 & PV 216W & PV 216E \\
Piémont-II & Control & PV -25 & PV +25 & PV 216W & PV 216E \\
\hline
\end{tabular}

adjoint variables $\hat{u}, \hat{v}$ and $\hat{\psi}\left(\hat{\psi}=\partial_{y} \hat{u}-\partial_{x} \hat{v}\right)$, an elliptic equation for $\hat{q}$ is obtained (see Appendix for details):

$\nabla_{p}^{2} \hat{q}_{k}+\gamma_{1} \hat{q}_{k}+\gamma_{2} \hat{q}_{k+1}-\gamma_{3} \hat{q}_{k-1}=\partial_{y} \hat{u}-\partial_{x} \hat{v}$

where the $\gamma_{i}$ parameters depend on the reference stability parameter $\sigma_{r}$ and the discretization scheme for Eq. (7). Solving Eq. (8) iteratively, the sensitivities of the response functions to modifications in the QPV fields are derived from the adjoint model variables $\hat{u}$ and $\hat{v}$.

The sensitivity field to the QPV at $330 \mathrm{~K}$ isentrope for each case is shown in Fig. 9. The Catalogne and Cévennes maps exhibit elongated distributions of PV, and the associated sensitivity patterns point primarily to their west and south sides. This is reasonable and consistent with the previously described evolution of the synoptic pattern, as these areas with high sensitivity evolve with the trough and are later likely involved in the configuration of the low-levels flow. Both Figs. 9a and $\mathrm{b}$ show areas with also notable sensitivity far to the east of the trough, over the Western Mediterranean, being more intense for the Cévennes case (Fig. 9b). Since these sensitivity structures are not related to intense PV features in the initial analysis, their physical interpretation is not clear beyond an indirect effect on the eastward progressing structures associated with the main trough. Regarding the Piémont-I and Piémont-II simulations, the distribution of high values of $\mathrm{PV}$ is less confined and so the sensitivity fields exhibit also larger structures that are not focused on the regions of strong PV gradient.

In summary, for all four sensitivity experiments, the adjoint results highlight various aspects of the precursor upperlevel trough, with special emphasis to its location and intensity. Provided that the precise details of the sensitivity fields are unreliable owing to the approximations used to derive them, it is however appropriate to focus the sensitivity test experiments with the PV inversion strategy and the forward model on general aspects of the precursor troughs, such as the location and intensity. These simplified sensitivity tests are developed in next section using as reference the PV signatures indicated with thick dashed line in Fig. 9.

\section{Results of the perturbed simulations and discussion}

Following the piecewise PV inversion methodology, four additional simulations were performed for each flash flood event by perturbing the initial intensity or position of the upper-level precursor trough. This was done by inverting the PV signatures defined in last section (see Fig. 9) and subtracting - or adding $-25 \%$ of the inverted fields to the initial conditions (perturbation of the trough intensity), and displacing these fields westwards - or eastwards - a distance of about $200-300 \mathrm{~km}$ (perturbation of the trough position). Table 1 summarizes the full set of simulations performed in the study and how these simulations are referred to in the text. Next, the results of these perturbed experiments are discussed and conclusions on the predictability of the events are derived.

\subsection{Catalogne event}

The type and amount of the perturbations introduced in the short-scale trough of this event can be appreciated in Fig. 10, to be compared with the control upper-level structure shown in Fig. 1a. All perturbed situations clearly reflect the same synoptic circulation pattern, and at first glance, the small changes imposed on the trough would even become undetected. Stated differently, the arbitrary perturbations introduced in the initial conditions appear to be compatible with the existing uncertainty in real-time operations.

The PV -25 experiment (Fig. 10a) is characterized by a weaker trough (this is especially noted off the coast of Galicia where the curved jet along the southern part of the trough is diminished and the air temperature is increased), and as expected, the rapidly evolving pattern at upper levels slows its motion. For instance, on 10 June at 00:00 UTC and comparing with the control situation shown in Fig. 1b, the trough has not yet reached the eastern coast of Spain and is more meridionally tilted (map not shown). Since this event was linked to a rapid baroclinic cyclogenesis in response to the forcing imposed from upper-levels, changes in the surface cyclone and associated rainfall have to be expected in the PV -25 run. In effect, a cyclone still develops (Fig. 11a), although slightly weaker and centred to the southwest of the control position (recall Fig. 2a). In essence, the cyclone is not as intense and it is far more stationary than the control one owing to the weaker and slower pattern at upper levels. At the end of the simulation, for instance, it is still located in between the Gulf of Valencia and the Balearics, while the control one did already left the Catalan coast behind (not shown). However, as a consequence of the enhanced stationarity, the inflow of moist and warm Mediterranean air 

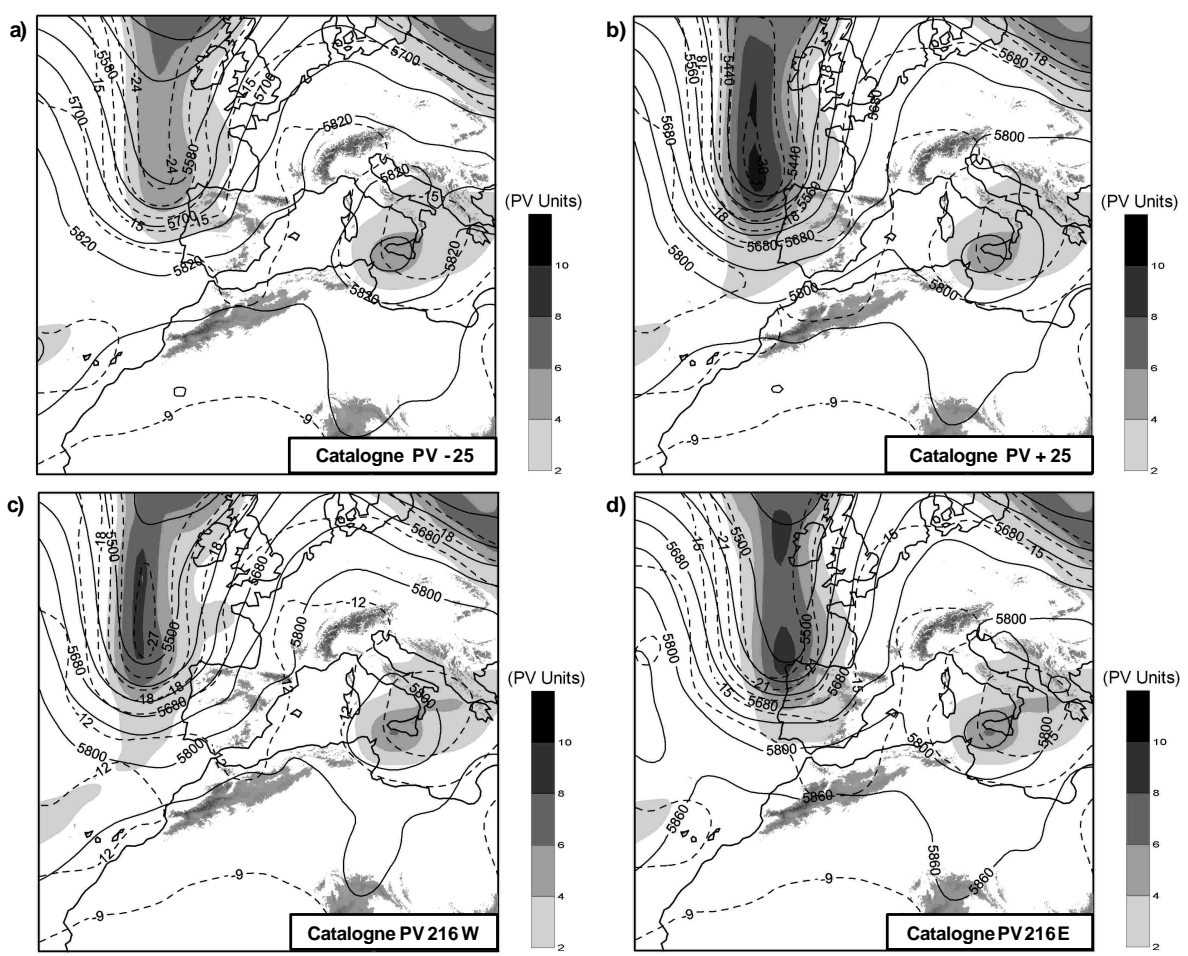

Fig. 10. Perturbed simulations of the Catalogne event for the coarse domain, showing the same fields as in Fig. 1a for the experiments: (a) PV -25; (b) PV +25; (c) PV 216W; and (d) PV 216E.
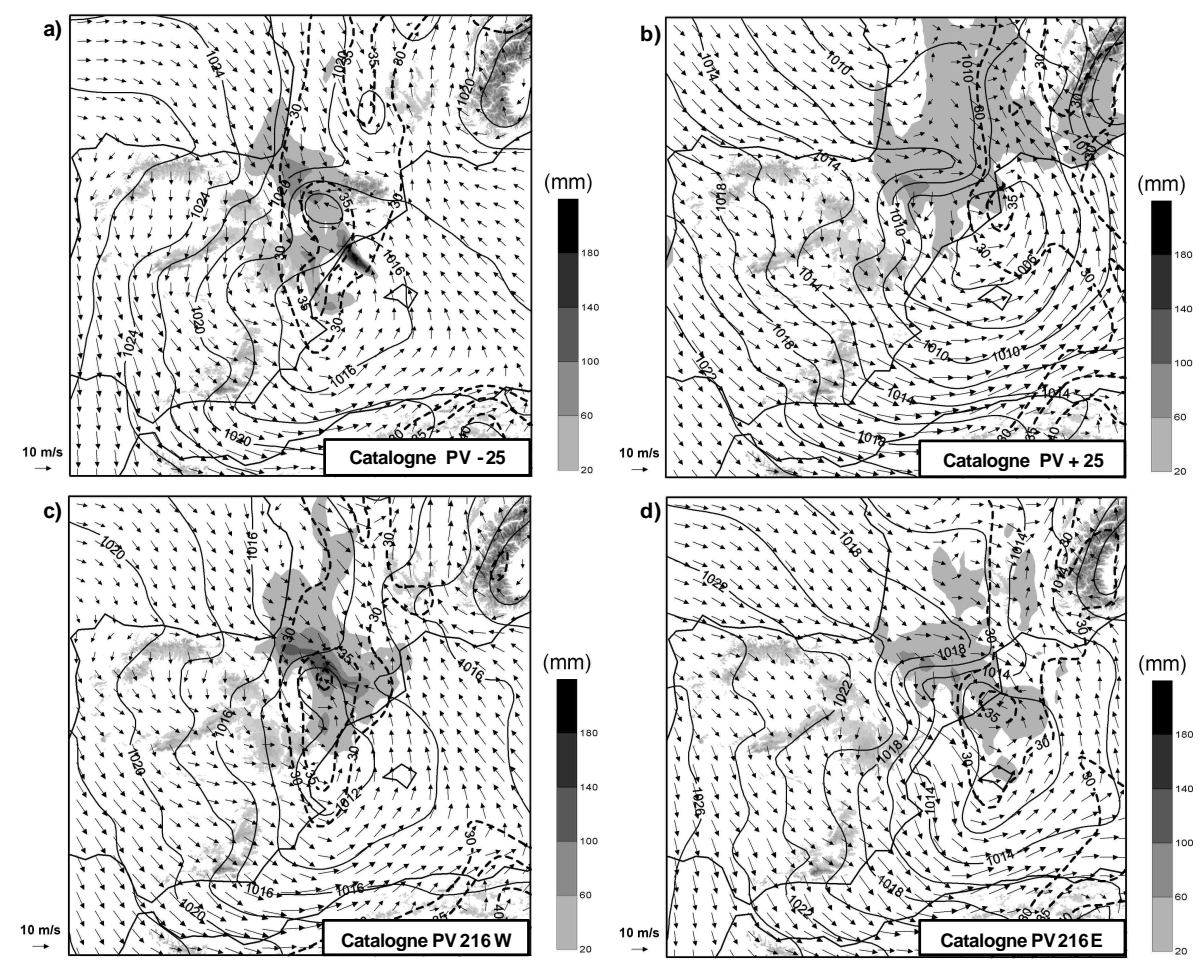

Fig. 11. Perturbed simulations of the Catalogne event for the fine domain, showing the same fields as in Fig. 2a for the experiments: (a) PV -25; (b) PV +25; (c) PV 216W; and (d) PV 216E. Maximum precipitation value in (a), (b), (c) and (d) is 230, 91,157 and $79 \mathrm{~mm}$, respectively. 

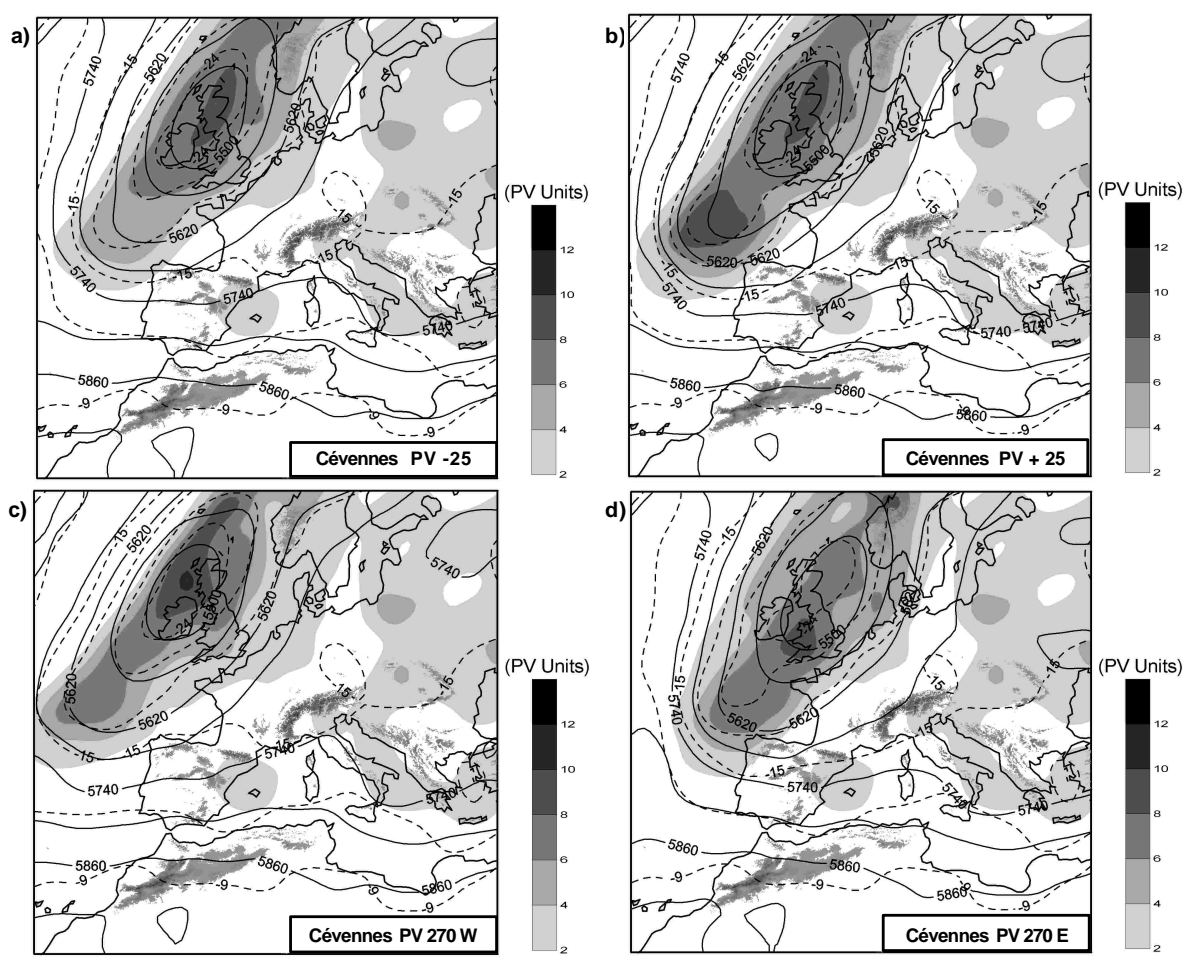

Fig. 12. Perturbed simulations of the Cévennes event for the coarse domain, showing the same fields as in Fig. 3a for the experiments: (a) PV -25; (b) PV +25; (c) PV 270W; and (d) PV 270E.

towards the Iberian Peninsula lasts many hours and the precipitation potential of the cyclone is very high $(230 \mathrm{~mm}$ maximum accumulated rainfall vs. 165 in the control one). Since the moisture convergence induced by the cyclone occurs farther south and west compared with the control situation, the resulting heavy precipitation field is simulated about 100 $150 \mathrm{~km}$ south and west of the affected areas.

In contrast with the previous experiment, the PV +25 simulation results in a more intense upper-level trough (Fig. 10b), and accordingly, a faster evolution during the simulated period occurs. In this case, the negative tilting experienced by the trough as it advanced over the Iberian Peninsula is more rapid, and the surface cyclone is slightly more intense and its displacement along the eastern coast of Spain into southern France is faster (compare Fig. 11b with Fig. 2a). However, even with a dynamically stronger situation and deeper cyclone, the heavy precipitation potential of this situation is clearly reduced owing to the reduced stationarity of the system. Appreciable rainfall over Catalogne is only simulated over the Pyrenees (Fig. 11b), since the system moves too fast as to bring enough moisture in a persistent way from the Mediterranean zone into the Catalan environment.

The translational speed of the surface cyclone seems then an important factor, as it is its position as well. The experiments with slightly displaced upper-levels troughs (PV 216W and PV 216E) serve to demonstrate this idea. The effects of perturbing the trough position but not its intensity (Figs. 10c and d) are reflected during the simulations on al- most identical evolutions at upper-levels to the control one except that the final troughs are located slightly westward and eastward of the reference trough, respectively. As a consequence, the forecast surface cyclones exhibit essentially the same translational speed as the control one (see Figs. 11c and $d$ in comparison with Fig. 2a), but their positions are found some tenths of kilometres westward and eastward, respectively. This has a deep impact on the forecast rainfall: the PV 216W cyclone is able to interact with the terrain features of Catalogne and the resulting rainfall is not very different to the control distribution, except for a tendency for generating heavy precipitation further inland (Fig. 11c); in contrast, the PV 216E cyclone evolves too far from the Catalan coast and the interaction of the cyclone induced moist flow and upward vertical motion with the topography of the region is not as effective (Fig. 11d).

In summary, our hypothesis that even small errors in the forecast cyclone characteristics could lead to appreciable changes in the spatial and quantitative details of the precipitation field appears to be true. This has to be attributed to the mesoscale size of the Catalogne cyclone and the fact that a very specific flow is necessary for an effective interaction of the moisture-rich Mediterranean air with the topography of the region. Of particular significance is the result that a certain degree of stationarity of the system is necessary to maintain the environmental ingredients in place for the heavy precipitations to occur: too fast or too distant cyclones simply result in much lower rainfall, whereas slow and near cyclones exhibit high precipitation potential. In any case, moreover, 
the precipitation spatial distribution is extremely sensitive to the cyclone characteristics.

\subsection{Cévennes event}

The perturbed upper-level troughs for Cévennes are displayed in Fig. 12, which should be compared with Fig. 3a. The changes in intensity are especially visible over the southwestern part of the positively tilted trough, and the changes in position are most evident taking as reference the position of its axis in relation to the northwest coast of Spain and France. In any case, the evolution of the upper-level synoptic pattern follows very closely the control evolution shown in Figs. 3a and $b$, that is, a large-scale cutoff low develops, centred just west of Ireland. Towards the end of the episode the upperlevel synoptic structures of the ensemble are hardly distinguishable from each other, as if the dynamical evolution of the event acted to filter in great extent the initial perturbations (maps not included). It seems, then, that the large scale nature of the precursor trough tends to minimize the effects of the typical errors committed in the representation of the initial state.

The specific effects on the flash-flood local environment and forecast rainfall can be appreciated in Fig. 13, to be compared with the control experiment in Fig. 4a. First of all, experiments $\mathrm{PV}-25$ and $\mathrm{PV}+25$ result in slightly weaker and stronger pressure gradients, respectively, over the western Mediterranenan (Figs. 13a and b). However, the sea level pressure field preserves its pattern. That is, the key feature for the precipitation control of this event (the southerly LLJ) preserves its position and direction and is simply slightly weakened and enhanced in PV -25 and PV +25 , respectively. We should then expect a proportional effect in the rainfall amounts but not significant modifications of the precipitation spatial pattern. Figures 13a and b show indeed an almost identical spatial distribution of the accumulated rainfall to the control experiment (Fig. 4a), and regarding the peak amount, 309 and $438 \mathrm{~mm}$ are respectively obtained, while in the control experiment it was $367 \mathrm{~mm}$.

Greater mesoscale effects are found in the experiments with perturbed trough positions, PV 270W and PV 270E, shown in Figs. 13c and d, respectively. What is found is a greater sensitivity of the sea level pressure field that is propagated into the rainfall field through the LLJ modification. In broad terms, the LLJ is focused towards land areas located slightly to the west and to the east, respectively, of the control jet. The LLJ direction is also affected, being more southeasterly and southwesterly, respectively, in PV 270W and PV 270E than in the control experiment. The forecast precipitation in both experiments is lower than in the control experiment (peak rainfalls are 211 and $183 \mathrm{~mm}$ ), and the precipitation structure in PV $270 \mathrm{~W}$ is particularly displaced westwards in coherence with the respective perturbation of the upper-level trough position.

Despite some effects have been detected in the forecast rainfall of the Cévennes episode, especially in its quantitative aspects, these effects are unambiguously lower than in the previous Catalogne event for similar perturbations of the initial PV. The location of the general structure of heavy precipitation is particularly insensitive to the initial perturbations. Thus, our basic hypothesis that the predictability of these LLJ-controlled flash flood events, essentially regulated by large-scale processes, is significantly high appears to be confirmed by the experiments. Moreover, it seems that both the action of the Alps range in enhancing the LLJ along its western flank and the role of the local topography in providing upward motion to the low-level moist parcels are dominant aspects which enhance the predictability of this kind of events.

\subsection{Piémont-I event}

The Piémont-I case was highlighted in last section as another example of LLJ-dominated flash-flood event, a prototypic situation of the Alpine heavy precipitation phenomenology. Therefore, it should be expected a relative insensitivity of the rainfall forecast to perturbations of the upper-level trough as long as these perturbations do not drastically affect the LLJ configuration. The perturbed initial states are shown in Fig. 14. Again, the effect of these perturbations is most clearly noticed over the southern part of the Atlantic trough, and compared with the Cévennes event, in this case the perturbed structures of the troughs are revealed in higher degree during its approach to the Iberian Peninsula (evolutions not shown). The secondary cyclogenesis that was noted near the eastern coast of Spain is quite sensitive to the upper-level modifications (Fig. 15). The resulting cyclone is stronger in $\mathrm{PV}+25$ and PV $216 \mathrm{E}$ experiments than in the control run (Figs. 15b and d vs. Fig. 6a). In contrast, it is appreciable weaker in PV -25 and PV $216 \mathrm{~W}$ experiments (Figs. 15a and c). Apart of being much weaker, the cyclone in these two experiments develops farther west, over the Iberian Peninsula.

It was noted in last section that the impinging LLJ over the Piémont region was associated, on one hand, with the largescale low-pressure area lying over western Europe and the eastern Atlantic, and on the other hand, with the enhancement action provided by the abovementioned secondary cyclone. Therefore, impacts on the strength of the LLJ have to be expected in coherence with the secondary cyclone modifications. In effect, the low-level flow direction over the western Mediterranean remains practically unchanged among the ensemble of experiments (Figs. 15 and 6a), but the wind speed is increased in the experiments with deeper and closer cyclones (PV +25 and PV 216E) and decreased in the experiments with smoother and more distant cyclones (PV -25 and PV 216W). Accordingly, the total precipitation amounts simulated by these experiments attain 194 and $186 \mathrm{~mm}$ in the first case, and 127 and $122 \mathrm{~mm}$ in the second case, that can be compared with an intermediate control value of $157 \mathrm{~mm}$. However, the spatial distribution of the precipitation field ahead of the cyclone is quite uniform among the ensemble of experiments, with only some remarkable differences along the coastal areas. Over Catalogne and Balearic Sea the 

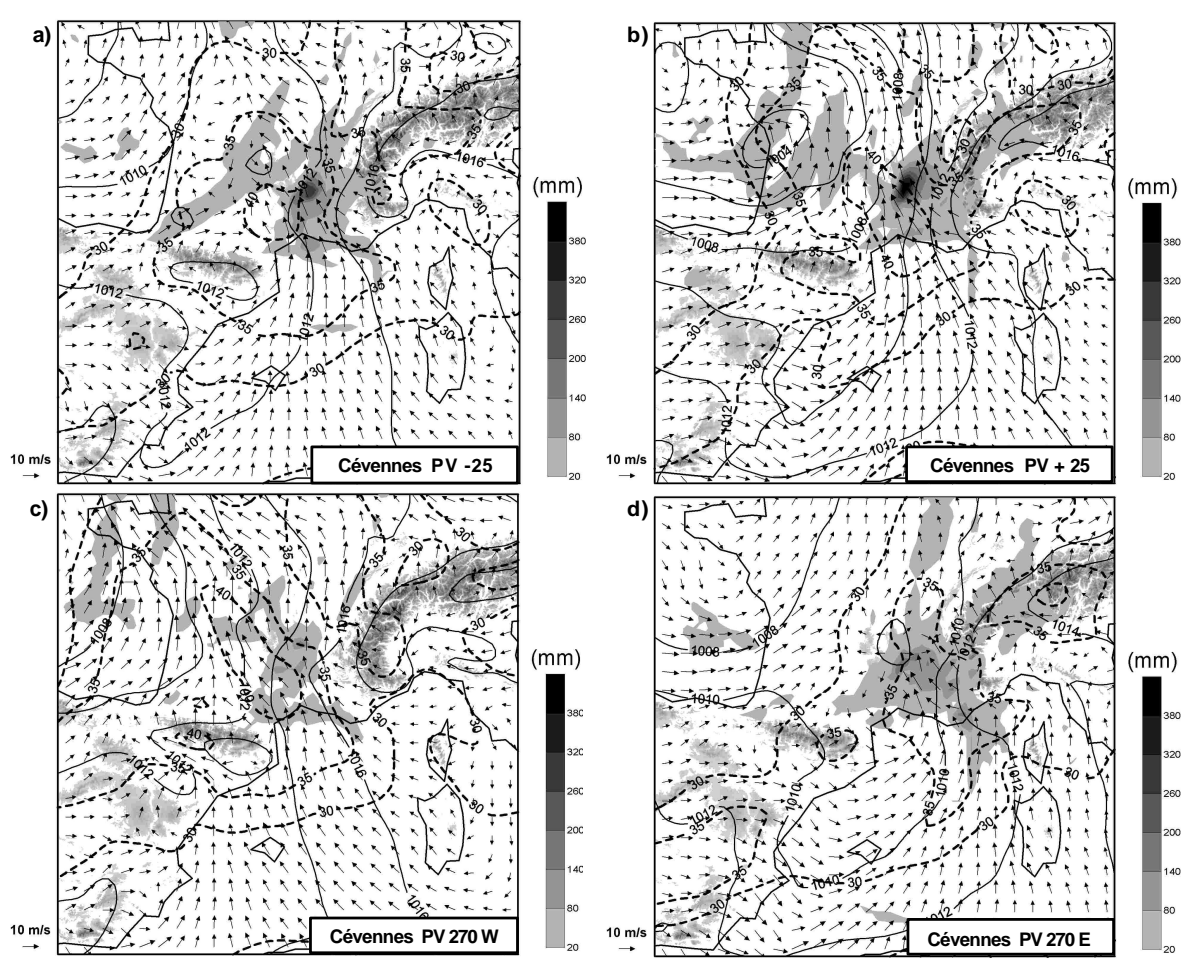

Fig. 13. Perturbed simulations of the Cévennes event for the fine domain, showing the same fields as in Fig. 4a for the experiments: (a) PV -25; (b) PV +25; (c) PV 270W; and (d) PV 270E. Maximum precipitation value in (a), (b), (c) and (d) is 309, 438, 211 and 183 mm, respectively.
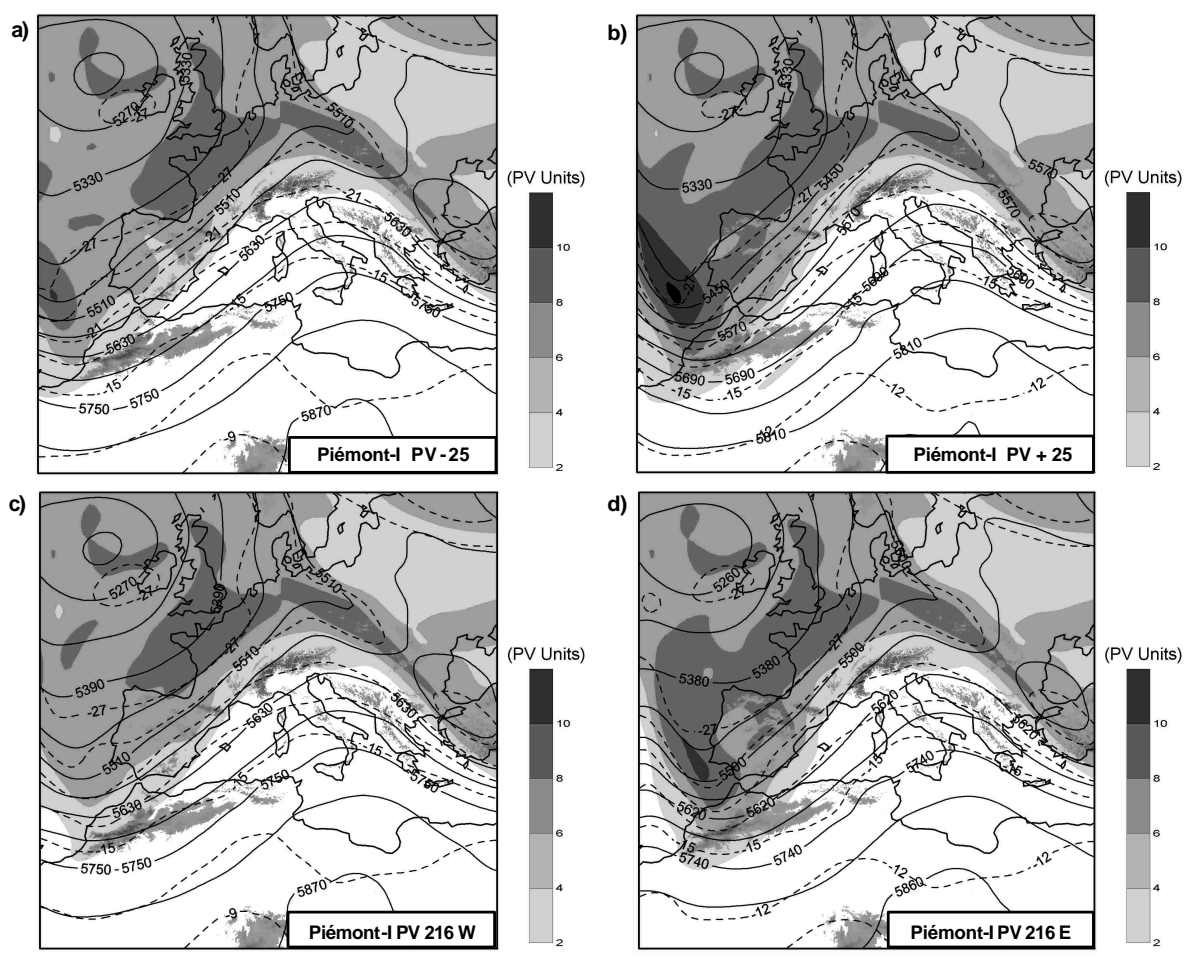

Fig. 14. Perturbed simulations of the Piémont-I event for the coarse domain, showing the same fields as in Fig. 5a for the experiments: (a) PV -25; (b) PV +25; (c) PV 216W; and (d) PV 216E. 

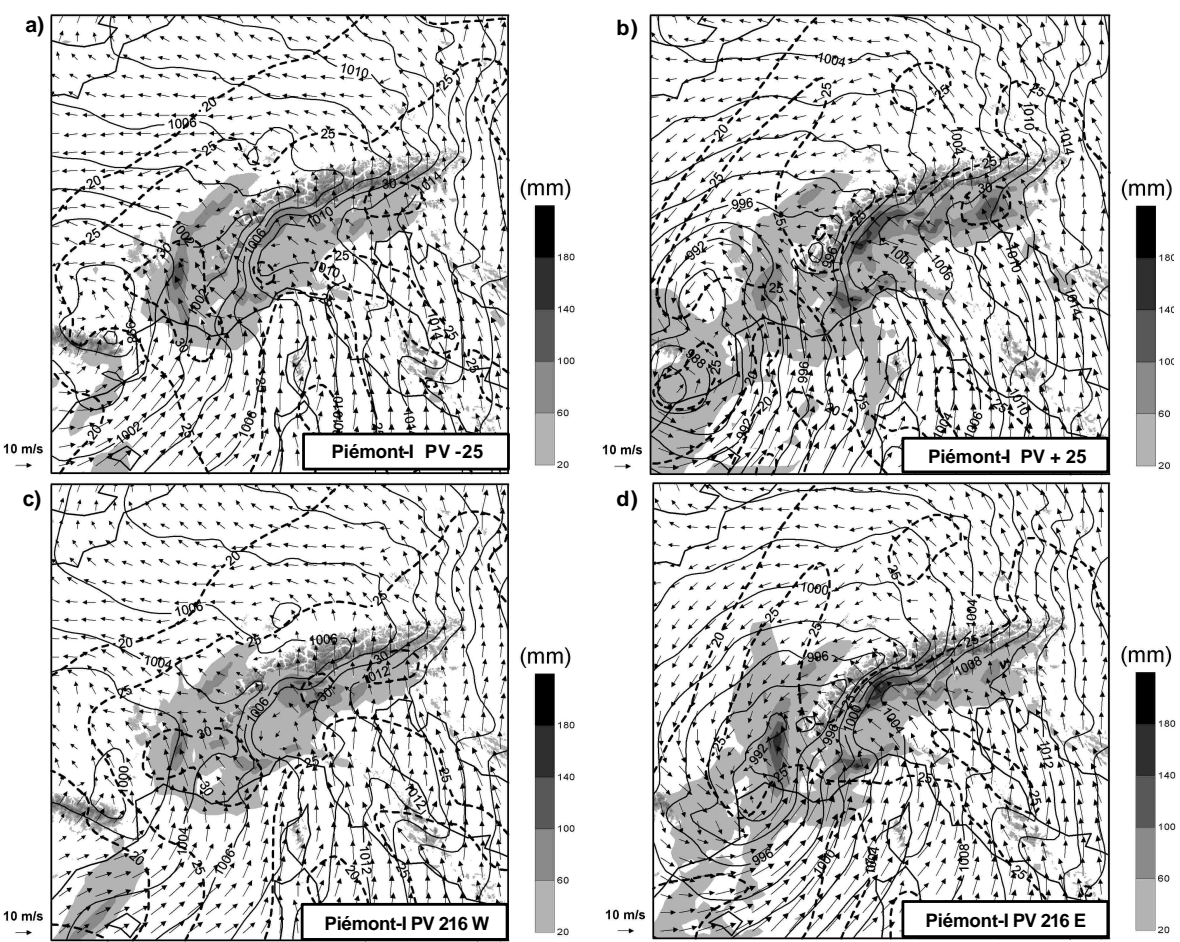

Fig. 15. Perturbed simulations of the Piémont-I event for the fine domain, showing the same fields as in Fig. 6a for the experiments: (a) PV -25; (b) PV +25; (c) PV 216W; and (d) PV 216E. Maximum precipitation value in (a), (b), (c) and (d) is 127, 194, 122 and 186 mm, respectively.

differences are more appreciable since these areas are more directly affected by the cyclone track.

Some resemblances to the Cévennes event are found for this event in regard to the final effects on the forecast rainfall by the uncertainties of the upper-level precursor trough. Namely, a moderate effect on quantitative precipitation but a very limited effect on its spatial distribution about the Alpine region. Clearly, guidance for flash flood potential in the Piémont region would have been equally attributed to any of the simulated scenarios. As opposite to the Cévennes event, a near cyclone played an important role in this case, but since this cyclone was relatively large (compare with the Catalogne event) and the affected area lied to its east-northeast, even an appreciable error in the cyclone evolution along the Iberian Peninsula did not really affect the Mediterranean LLJ responsible for the heavy precipitations over the topographically complex Piémont area.

\subsection{Piémont-II event}

Since the Piémont-II event was characterized by the genesis of a cyclone in the western Mediterranean basin, then greater local effects can be expected over the area in association with perturbed cyclone properties. The upper-level trough in this case was modified as displayed in Fig. 16. The PV +25 and PV 216E situations clearly exhibit stronger troughs than the PV -25 and PV $216 \mathrm{~W}$ cases. Attending to the evolution of the upper-level circulation pattern (not shown) it is also found deeper disturbances in the former situations than in the later experiments near the end of the episode. However, the trough position and tilting in the perturbed experiments are very similar to the control one (Fig. 7b) except for PV 216W for which the final trough is more meridionally oriented.

The stronger upper-level systems constructed through the PV +25 and PV 216E perturbations lead to Mediterranean surface cyclones deeper than the control one (compare Fig. 17b and d with Fig. 8a), whereas this cyclone is weaker in the PV -25 and PV 216W experiments (Figs. 17a and c). Regarding the cyclone position and structure, the greatest changes with respect to the control attributes are found for the PV $216 \mathrm{~W}$ cyclone, which centre is located appreciably north of the reference position and the cyclone itself is more elongated in the meridional direction. Such greater response is linked to the equally greater response of the upper-level trough evolution to the initial PV 216W perturbation.

It is now interesting to examine the effects on the forecast rainfall associated with the local cyclone (see the total precipitation fields in Figs. 17 and 8a). First of all, no clear association emerges between the peak rainfall and the depth of the Mediterranean cyclone. For instance, the deepest PV 216E cyclone reaches $177 \mathrm{~mm}$, the minimum value among the experiments. However, the cyclone proximity to the Piémont region seems to exert a greater control and the smoother but closer PV 216W cyclone reaches as much as $240 \mathrm{~mm}$, the maximum value among the experiments. In second place, much higher sensitivities to the cyclone characteristics are found over the sea and coastal areas than over 

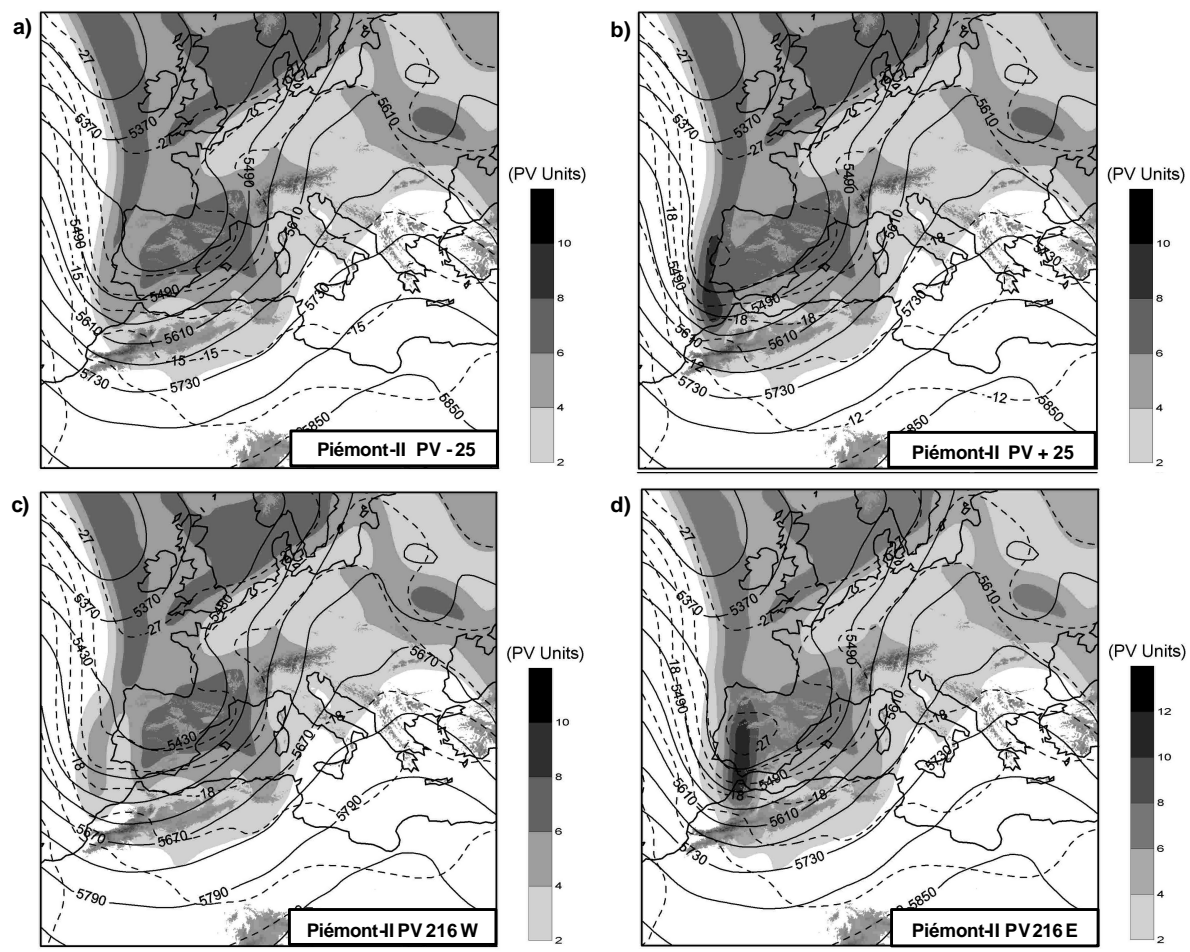

Fig. 16. Perturbed simulations of the Piémont-II event for the coarse domain, showing the same fields as in Fig. 7a for the experiments: (a) PV -25; (b) PV +25; (c) PV 216W; and (d) PV 216E.

inland mountainous zones. This fact basically illustrates that the former areas are directly affected by the cyclone itself and therefore changes in its evolution and structure affect significantly the precipitation field, whereas the latter zones are more indirectly affected by the system while the topographical influences play a crucial role. The Mediterranean low-level moist flow against the Alps slopes is a permanent feature of this ensemble of experiments and therefore the precipitation response in those areas is relatively insensitive, spatially speaking, to the initial perturbations.

In comparison with the Catalogne event we have then found a smaller degradation of numerical prediction from uncertainties of the upper-level precursor trough. This could have been anticipated since the influencing local cyclone is larger in this case than in Catalogne. Nevertheless, we have found moderate response of the rainfall forecasts in those areas most directly affected by the cyclone and where topographical influence is weak or absent. Similarly to the Cévennes and Piémont-I event, quantitative precipitation forecasts over the topographic complex areas appears to be moderately sensitive to the precise features of the low-level circulation, while the spatial distributions are essentially insensitive.

\section{Conclusions}

The predictability of the HYDROPTIMET flash flood events has been analysed using synthetic synoptic scenarios that at- tempt to capture some of the typical uncertainties present in real-time NWP systems: a deficient knowledge of the precise position and intensity of the upper-level precursor trough. A methodology that combines Adjoint sensitivity calculations in terms of the potential vorticity field with a piecewise PV inversion technique to construct perturbed mesoscale simulations has been shown to be very practical and effective for that purpose. We believe that an operational adaptation of the system, where the Adjoint method provides guidance on the main sensitivity areas and the PV inversion technique is used to alter initial conditions in a physically consistent way, could be very useful for designing real-time mesoscale ensemble prediction systems. The implementation of the method could be fully automatic if the response function for the Adjoint calculations was objectively defined, for example in terms of some prescribed physical attributes of cyclones detected near the area of interest, or could require the user intervention, trying to choose influential features of the flow as the most appropriate response functions of the day. In addition, for an effective application of the system to ensemble forecasting the initial perturbations should be bounded by the climatology of analysis error variance expressed in terms of PV, a constraint that has been obviated in the present work.

In this study a short ensemble of simulations was performed for just four flash-flood events, but the obtained results appear to be sufficiently representative as to permit some basic conclusions on the predictability of flash flood situations in the Western Mediterranean. It should be noted that "predictability" in this study has been subjectively 

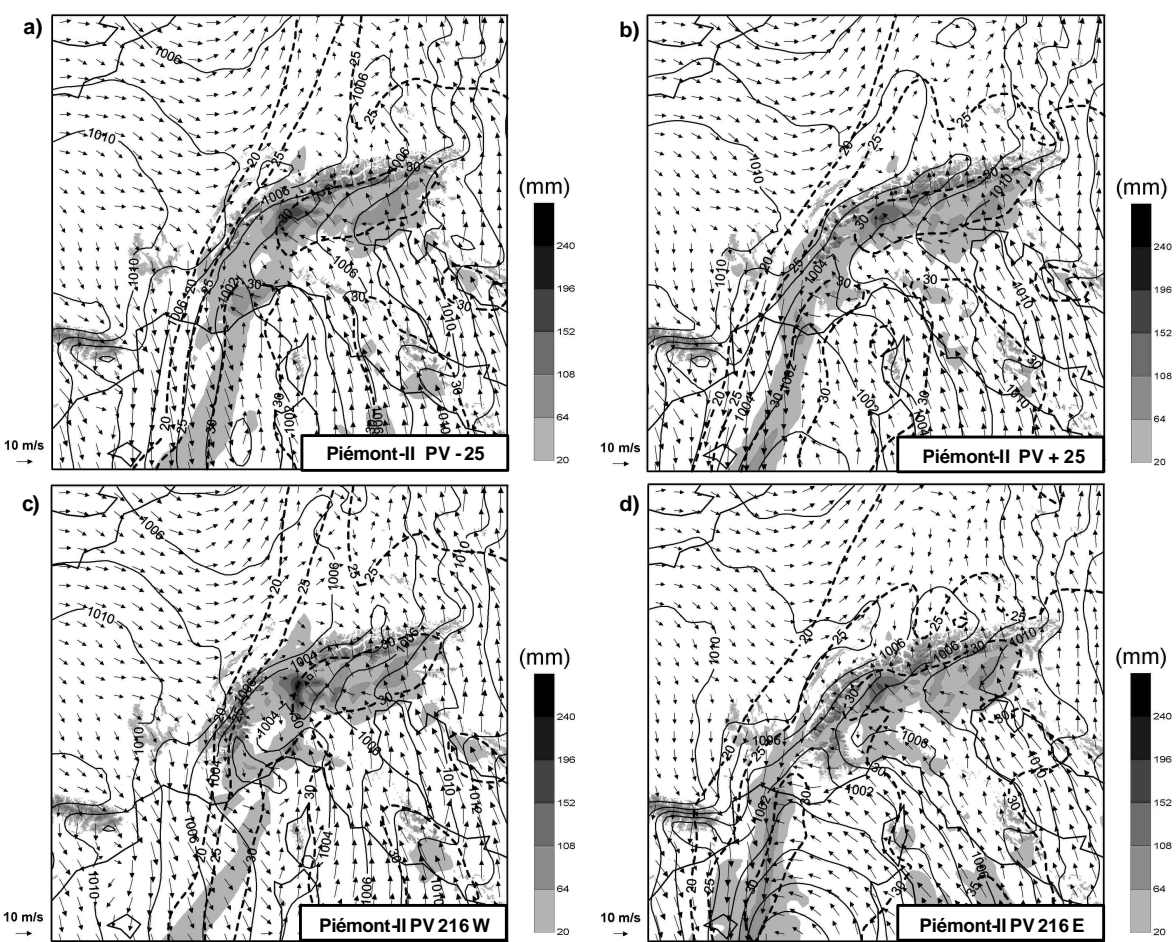

Fig. 17. Perturbed simulations of the Piémont-II event for the fine domain, showing the same fields as in Fig. 8a for the experiments: (a) PV -25; (b) PV +25; (c) PV 216W; and (d) PV 216E. Maximum precipitation value in (a), (b), (c) and (d) is 196, 205, 240 and $177 \mathrm{~mm}$, respectively.

associated to the model capability of providing good guidance of the flash-flood potential of each situation and a reasonably correct localization of the affected areas. That is, what a weather forecaster would consider as crucial information to activate any generic warning or emergency procedure. However, hydrological considerations are omitted in the study being aware of the current limitations of mesoscale prediction systems for providing good quantitative precipitation forecasts at watershed scale.

A rich variety of synoptic and mesoscale processes were identified among the HYDROPTIMET case studies using the control numerical simulations and additional experiments including non-topographic runs. The well established idea that the predictability of heavy precipitations in many Mediterranean areas is favoured by the complex topography emerged repeatedly during the course of the study. The Alpine events are probably the best example of strong topographical influence in action, without forgetting other well-known areas such as central Valencia in Spain (not considered in this study). A dominant role of the topography simply guarantees a reasonably correct spatial localization of the heavy precipitation areas in most of the situations, particularly under environmental settings governed by the large-scale dynamics rather than by mesoscale pressure systems. What it is necessary is a reasonably correct prediction of the low-level moist flow relative to the topography. In contrast, the notion that accurate quantitative forecasts are also favoured by the complex topography is not as obvious. We found that the quanti- tative values can be significantly sensitive to the uncertainties of the upper-level trough and the associated low-level flow system. Even over the Alpine/southern France region and for synoptically dominated flash flood conditions, small errors in the LLJ intensity and/or direction can produce notable differences in the rainfall amounts. It is interesting to point out that the misplacement of the precipitation centre in the Cévennes simulation could not be alleviated by any of the PV perturbed experiments. The triggering and maintenance of the convection in this event was linked to the orography but, strictly speaking, much of the precipitation was not directly orographic since it occurred in lowland areas. Apparently, the lack of mesonet network surface data in the model initial conditions is at least partially responsible for the model tendency to focus the precipitation centre towards the mountain slopes (see Ducrocq et al., 2004).

A second type of predictability limitation was emphasized for those situations or areas where a local cyclone exerted a higher control of the flash-flood ingredients. In those circumstances, even small forecast errors of the cyclone attributes might drastically affect the quality of the forecast rainfall. It can be concluded that the smaller is the surface cyclone, the greater will be the forecast degradation under the typical errors of the upper-level precursor trough. Interestingly, a certain level of stationarity of the cyclone rather than its particular intensity appears to be the most critical factor for the development and persistence of flash flood conditions in some cases. 
Finally, it should be noted that the selected flash-flood events obviously do not describe the wide variety of flashflood scenarios that affect any given region in the Western Mediterranean. Flash floods in Catalogne are also produced by easterly flows associated with large-scale pressure patterns, and notable events in the Alpine region can occur under the direct action of small mesoscale lows. Numerous examples of virtually any kind of heavy rain producing meteorological pattern would easily be found for Catalogne, Cévennes, Piémont, Valencia, south Italy, North Africa and any other place. What it is expected from this study is to encourage weather forecasters and researchers to make a clear discrimination of the meteorological scenario (large-scale vs. mesoscale; local cyclone vs. remote cyclone; fast cyclone vs. slow cyclone; topographical influence vs. topographyfree situation; LLJ presence, duration and persistence vs. LLJ absent; moisture availability vs. moisture deficit; etc.) when attempting to assign a confidence level to a deterministic forecast.

\section{Appendix A}

\section{Calculation of sensitivity to the quasigeostrophic potential vorticity}

The quasigeostrophic PV (q) is related to the geostrophic streamfunction $(\psi)$ as:

$q=\nabla_{p}^{2} \psi+f+f_{0}^{2} \partial_{p}\left(\frac{1}{\sigma_{r}} \partial_{p} \psi\right.$

With $f$ the coriolis parameter and $\sigma_{r}$ a reference stability parameter:

$\sigma_{r}=-\frac{\alpha}{\theta} \frac{d \theta_{r}(p)}{d p}$

The discretization of Eq. A1 over a regular horizontal grid and unequally spaced vertical levels is:

$$
\begin{aligned}
q & =\frac{\psi_{i+1}+\psi_{i-1}+\psi_{j+1}+\psi_{j-1}-4 \psi}{\Delta x^{2}}+f \\
& +\alpha_{k}\left(a^{\prime} \psi+b^{\prime} \psi_{k-1}+c^{\prime} \psi_{k+1}\right) \\
& +\beta_{k}\left(a^{\prime \prime} \psi+b^{\prime \prime} \psi_{k-1}+c^{\prime \prime} \psi_{k+1}\right)
\end{aligned}
$$

with $\alpha_{k}=\mathrm{f}_{0}^{2} \partial_{p} 1 /\left.\sigma_{r}\right|_{k}, \beta_{k}=\mathrm{f}_{0}^{2} / \sigma_{r}$ and where a', a", b', b", c', c" depend on the particular vertical discretization used. For the sake of clarity, only indices different from the central point $i j k$ have been noted.

Using the Errico and Vukicevic (1992) hand transposition strategy term by term, the adjoint of Eq. A3 consists of:

$$
\begin{array}{ll}
\hat{\psi}_{i+1} \leftarrow \hat{q} / \Delta x^{2} & \hat{\psi} \leftarrow-4 \hat{q} / \Delta x^{2} \\
\hat{\psi}_{i-1} \leftarrow \hat{q} / \Delta x^{2} & \hat{\psi} \leftarrow\left(\alpha a^{\prime}+\beta a^{\prime \prime}\right) \hat{q} \\
\hat{\psi}_{j+1} \leftarrow \hat{q} / \Delta x^{2} & \hat{\psi}_{k-1} \leftarrow\left(\alpha b^{\prime}+\beta b^{\prime \prime}\right) \hat{q} \\
\hat{\psi}_{j-1} \leftarrow \hat{q} / \Delta x^{2} & \hat{\psi}_{k+1} \leftarrow\left(\alpha c^{\prime}+\beta c^{\prime \prime}\right) \hat{q}
\end{array}
$$

which can be recombined into a single equation for $\hat{\psi}$, namely:

$$
\begin{aligned}
\hat{\psi} & =\frac{\hat{q}_{i+1}+\hat{q}_{i-1}+\hat{q}_{j+1}+\hat{q}_{j-1}+4 \hat{q}}{\Delta x^{2}} \\
& +\left(\alpha a^{\prime}+\beta a^{\prime \prime}\right) \hat{q}+\left(\alpha_{k+1} b_{k+1}^{\prime}+\beta_{k+1} b_{k+1}^{\prime \prime}\right) \hat{q}_{k+1} \\
& +\left(\alpha_{k-1} c_{k-1}^{\prime}+\beta_{k-1} c_{k-1}^{\prime \prime}\right) \hat{q}_{k-1}
\end{aligned}
$$

Since $\hat{\psi}=\partial_{y} \hat{u}-\partial_{x} \hat{v}$ and defining $\gamma_{1}, \gamma_{2}$ and $\gamma_{3}$, we get an elliptic equation for $\hat{q}$ :

$\nabla_{p}^{2} \hat{q}_{k}+\gamma_{1} \hat{q}_{k}+\gamma_{2} q_{\hat{k}+1}-\gamma_{3} q_{\hat{k}-1}=\partial_{y} \hat{u}-\partial_{x} \hat{v}$

Acknowledgements. This research was developed under the objectives and financial support of Spanish project MEDEXIB (REN2002-03482/CLI) and Interreg IIIB-Medocc European project HYDROPTIMET (2002-02-4.3-I-079). Maps of observed precipitation during the flash flood events were provided by different partners involved in the second project. NCAR/Scientific Computer Division (sponsored by the National Science Foundation) and the Instituto Nacional de Meteorología (INM) of Spain are acknowledged for providing access to NCEP and ECMWF analyses, respectively.

Edited by: A. Buzzi

Reviewed by: two referees

\section{References}

Arbogast, P.: Sensitivity to potential vorticity, Quart. J. Roy. Meteor. Soc., 124, 1605-1615, 1998.

Benjamin, S. G.: Some effects of heating and topography on the regional severe storm environment, $\mathrm{Ph}$. D. thesis. The Pennsylvania State University, 265 pp [Available from University Microfilm, 300 N. Zeeb Rd., P.O. Box 1346, Ann Arbor, MI 46801-1346], 1983.

Benjamin, S. G. and Seaman, N. L.: A simple scheme for improved objective analysis in curved flow, Mon. Wea. Rev., 113, 11841198, 1985

Blackadar, A. K.: High resolution models of the planetary boundary layer. Advances in Environmental Science and Engineering, Vol. 1, No. 1, edited by: Pfafflin, J. and Ziegler, E., Gordon and Breach, 50-85, 1979

Buizza, R. and Palmer, T. N.: The SV structure of the atmospheric global circulation J. Atmos. Sci., 52, 1434-1456, 1995.

Charney, J. G.: The use of primitive equations of motion in numerical prediction, Tellus, 7, 22-26, 1955.

Davis, C. A. and Emanuel, K. A.: Potential vorticity diagnosis of cyclogenesis, Mon. Wea. Rev., 119, 1929-1953, 1991.

Davis, C. A.: A potential vorticity diagnosis of the importance of initial structure and condensational heating in observed extratropical cyclogenesis, Mon. Wea. Rev., 120, 2409-2428, 1992.

Deidda, R., Benzi, R., and Siccardi, F.: Multifractal modelling of anomalous scaling laws in rainfall, Water Resources Research, 35, 1853-1867, 1999.

Deidda, R.: Rainfall downscaling in a space-time multifractal framework, Water Resources Research, 36, 1779-1794, 2000.

Doswell III, C. A., Ramis, C., Romero, R., and Alonso, S.: A diagnostic study of three heavy precipitation episodes in the western Mediterranean region, Wea. Forecasting, 13, 102-104, 1998. 
Ducrocq, V., Chancibault, K., Habets, F., and Anquetin, S.: High resolution numerical prediction of the 2002 Gard extreme flashflood: Sensitivity to initial conditions and surface conditions, EGS Plinius Conference on Mediterranean Storms V, CD-ROM, 2004.

Dudhia, J.: Numerical study of convection observed during the winter monsoon experiment using a mesoscale two-dimensional model, J. Atmos. Sci., 46, 3077-3107, 1989.

Dudhia, J.: A nonhydrostatic version of the Penn State/NCAR mesoscale model: Validation tests and simulation of an Atlantic cyclone and cold front Mon. Wea. Rev., 121, 1493-1513, 1993.

Errico, R. M.: What is an adjoint model?, Bull. Am. Meteorol. Soc., 78, 2577-2591, 1997.

Fehlmann, R., Quadri, C., and Davies, H. C.: An alpine rainstorm: Sensitivity to the mesoscale upper-level structure, Wea. and Forecasting, 15, 4-28, 2000.

Ferraris, L., Rudari, R., and Siccardi, F.: The uncertainty in the prediction of flash floods in the Northern Mediterranean environment, J. Hydrometeorol., 3, 714-727, 2002.

Grell, G. A., Dudhia, J., and Stauffer, D. R.: A description of the fifth-generation of the Penn State/NCAR mesoscale model (MM5), NCAR Tech. Note NCAR/TN-398+STR, Boulder, USA, 1995.

Hakim, G. H., Keyser, D., and Bosart L. F.: The Ohio valley wavemerger cyclogenesis event of 25-26 January 1978. Part II: Diagnosis using quasigeostrophic potential vorticity inversion, Mon. Wea. Rev., 124, 2176-2205, 1996.

Hamill, T. M., Mullen, S. L., Snyder, C., Toth, Z., and Baumhefner, D. P.: Ensemble forecasting in the short to medium range: Report from a workshop,Bull. Amer. Meteor. Soc., 81, 2653-2664, 2000.

Homar, V., Romero, R., Ramis, C., and Alonso, S.: Numerical study of the October 2000 torrential precipitation event over eastern Spain: Analysis of the synoptic-scale stationarity, Ann. Geophys., 20, 2047-2066, 2002,

SRef-ID: 1432-0576/ag/2002-20-2047.

Homar, V. and Stensrud, D. J.: Sensitivities of an intense Mediterranean cyclone: Analysis and validation, Quart. J. Roy. Meteor. Soc., 130, 2519-2540, 2004.

Hong, S. Y., and Pan, H. L.: Nonlocal boundary layer vertical diffusion in a medium-range forecast model, Mon. Wea. Rev. 124, 2322-2339, 1996.

Hoskins, B. J., McIntyre, M. E., and Robertson, A. W.: On the use and significance of isentropic potential vorticity maps, Quart. J. Roy. Meteor. Soc., 111, 877-946, 1985.

Huo, Z., Zhang, D. L., and Gyakum, J. R.: Interaction of potential vorticity anomalies in extratropical cyclogenesis. Part I: Static Piecewise inversion, Mon. Wea. Rev., 127, 2546-2561, 1999.

Kain, J. S. and Fritsch, J. M.: A one-dimensional entraining/detraining plume model and its application in convective parameterization, J. Atmos. Sci., 47, 2784-2802, 1990.
Langland, R. H., Shapiro, M. A, and Gelaro, R.: Initial Condition Sensitivity and Error Growth in Forecasts of the 25 January 2000 East Coast Snowstorm, Mon. Wea. Rev., 130, 957-974, 2002.

Mass, C. F. and Kuo, Y. H.: Regional real-time numerical weather prediction: Current status and future potential, Bull. Amer. Meteor. Soc., 79, 253-263, 1998.

Morgan, M. C: Using piecewise potential vorticity inversion to diagnose frontogenesis. Part I: Partitioning of the $\mathrm{Q}$ vector applied to diagnosing surface frontogenesis and vertical motion, Mon. Wea. Rev., 127, 2796-2821, 1999.

Murphy, A. H.: The impact of ensemble forecasts on predictability, Quart. J. Roy. Meteor. Soc., 114, 463-493, 1988.

Petroliagis, T., Buizza, R., Lanzinger, A., and Palmer, T. N.: Extreme rainfall prediction using the European Center for MediumRange Weather Forecast ensemble prediction system, J. Geophys. Res., 101, 26 227-26 236, 1996.

Reisner, J., Rasmussen, R. J., and Bruintjes, R. T.: Explicit forecasting of supercooled liquid water in winter storms using the MM5 mesoscale model, Quart. J. Roy. Soc., 124B, 1071-1107, 1998.

Roebber, P. J., Schultz, D. M., Colle, B. A., and Stensrud, D. J.: Toward improved prediction: High-resolution and ensemble modelling systems in operations, Wea. Forecasting, 19, 936-949, 2004.

Romero, R., Ramis, C., Alonso, S., Doswell III, C. A., and Stensrud, D. J.: Mesoscale model simulations of three heavy precipitation events in the western Mediterranean region, Mon. Wea. Rev., 126, 1859-1881, 1998.

Romero, R.: Sensitivity of a heavy rain producing Western Mediterranean cyclone to embedded potential vorticity anomalies, Quart. J. Roy. Meteor. Soc., 127, 2559-2597, 2001.

Stensrud, D. J., Bao, J., and Warner, T. T.: Using initial condition and model physics perturbations in short-range ensemble simulations of mesoscale convective systems, Mon. Wea. Rev., 128, 2077-2107, 2000.

Toth, Z., and Kalnay, E.: Ensemble Forecasting at NMC: The Generation of Perturbations, Bull. Amer. Meteor. Soc., 74, 23172330, 1993.

Zhang, D. L., and Anthes, R. A.: A high resolution model of the planetary boundary layer. Sensitivity tests and comparisons with SESAME-79 data, J. Appl. Meteor., 21, 1594-1609, 1982.

Zhang, D. L. and Fritsch, J. M.: Numerical simulation of the meso$\beta$ scale structure and evolution of the 1977 Johnstown flood. Part I: Model description and verification, J. Atmos. Sci., 43, 19131943, 1986.

Zou, X., Vandenberghe, F., Pondeca, M., and Kuo, Y.-H.: Introduction to adjoint techniques and the MM5 adjoint modelling system. NCAR Tech. Note NCAR/TN-435+IA, Boulder, USA, 1997.

Zou, X., Huang, W., and Xiao, Q.: A user's guide to the MM5 Adjoint Modeling System, NCAR Tech. Note NCAR/TN-437+IA, Boulder, USA, 1998. 